\title{
Neuronal Preconditioning Requires the Mitophagic Activity of C-terminus of HSC70-Interacting Protein
}

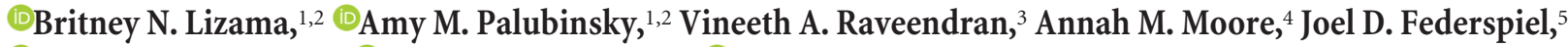 \\ (DSimona G. Codreanu, ${ }^{5}$ @Daniel C. Liebler, ${ }^{5}$ and ${ }^{-B e t h A n n ~ M c L a u g h l i n ~}{ }^{2,6,7}$ \\ ${ }^{1}$ Neuroscience Graduate Group, ${ }^{2}$ Vanderbilt Brain Institute, ${ }^{3}$ Vanderbilt International Summer Research Academy, ${ }^{4}$ Vanderbilt Interdisciplinary Graduate \\ Program, ${ }^{5}$ Department of Biochemistry, ${ }^{6}$ Department of Neurology, and 7 Department of Pharmacology, Vanderbilt University Medical Center, Nashville, \\ Tennessee 37240
}

The C terminus of HSC70-interacting protein (CHIP, STUB1) is a ubiquitously expressed cytosolic E3-ubiquitin ligase. CHIP-deficient mice exhibit cardiovascular stress and motor dysfunction before premature death. This phenotype is more consistent with animal models in which master regulators of autophagy are affected rather than with the mild phenotype of classic E3-ubiquitin ligase mutants. The cellular and biochemical events that contribute to neurodegeneration and premature aging in CHIP KO models remain poorly understood. Electron and fluorescent microscopy demonstrates that CHIP deficiency is associated with greater numbers of mitochondria, but these organelles are swollen and misshapen. Acute bioenergetic stress triggers CHIP induction and relocalization to mitochondria, where it plays a role in the removal of damaged organelles. This mitochondrial clearance is required for protection following low-level bioenergetic stress in neurons. CHIP expression overlaps with stabilization of the redox stress sensor PTEN-inducible kinase 1 (PINK1) and is associated with increased LC3-mediated mitophagy. Introducing human promoter-driven vectors with mutations in either the E3 ligase or tetracopeptide repeat domains of CHIP in primary neurons derived from CHIP-null animals enhances CHIP accumulation at mitochondria. Exposure to autophagy inhibitors suggests that the increase in mitochondrial CHIP is likely due to diminished clearance of these CHIP-tagged organelles. Proteomic analysis of WT and CHIP KO mouse brains (four male, four female per genotype) reveals proteins essential for maintaining energetic, redox, and mitochondrial homeostasis undergo significant genotype-dependent expression changes. Together, these data support the use of CHIP-deficient animals as a predictive model of age-related degeneration with selective neuronal proteotoxicity and mitochondrial failure.

Key words: autophagy; E3 ubiquitin ligase; HSP70; ischemic preconditioning; mitochondria; mitophagy

Significance Statement

Mitochondria are recognized as central determinants of neuronal function and survival. We demonstrate that $\mathrm{C}$ terminus of HSC70-Interacting Protein (CHIP) is critical for neuronal responses to stress. CHIP upregulation and localization to mitochondria is required for mitochondrial autophagy (mitophagy). Unlike other disease-associated E3 ligases such as Parkin and Mahogunin, CHIP controls homeostatic and stress-induced removal of mitochondria. Although CHIP deletion results in greater numbers of mitochondria, these organelles have distorted inner membranes without clear cristae. Neuronal cultures derived from animals lacking CHIP are more vulnerable to acute injuries and transient loss of CHIP renders neurons incapable of mounting a protective response after low-level stress. Together, these data suggest that CHIP is an essential regulator of mitochondrial number, cell signaling, and survival.

\section{Introduction}

The HSP70 complex is capable of blocking neurodegeneration triggered by a host of genetic mutations, physiological events and environmental stressors (Franklin et al., 2005; Gestwicki and Garza, 2012). HSP70-binding partners alter the localization, activity, and expression of the chaperone complex itself and its client proteins. E3 ligases such as Parkin and C terminus of HSC70-
This work was supported by Walter and Suzanne Scott Foundation funding of the J.B. Marshall Laboratory (B.M A.M.P., B.N.L.), the Dan Marino Foundation (B.M., A.M.P.), the National Institutes of Health (Grant NS050396 to B.M. and Grant R01ES022936 to B.M. and D.C.L.), a Vanderbilt Brain Institute Scholarship (B.N.L., A.M.P.), a VISRA Program Scholarship (V.A.R.), and predoctoral fellowships from the American Heart Association (Grant 15PRE25100000 to A.M.P. and Grant 14PRE2003500007 to B.N.L.). We thank Dr. Cam Patterson for providing the 
Interacting Protein (CHIP) regulate HSP70-mediated protein degradation (Ballinger et al., 1999; Jiang et al., 2001). CHIP is a 303 aa cytosolic protein that contains an N-terminal tetratricopeptide repeat (TPR) domain regulating HSP/HSC70 docking, a helixloop-helix domain, and a C-terminal Ubox domain that is necessary for binding to E2-conjugating enzymes (Ballinger et al., 1999; Jiang et al., 2001; Xu et al., 2008). CHIP is unique among E3 ligases in that its expression is induced by acute bioenergetic stress and in postmortem samples from patients with stroke (Stankowski et al., 2011; Lizama et al., 2018). CHIP is also unique in that it forms asymmetric homodimers, which have not been observed in other E3 ligase proteins and are only formed in higher vertebrates, suggesting that it may perform distinctive roles in cell biology (Zhang et al., 2005; Ye et al., 2017).

Further evidence of the uniqueness of CHIP can be found in studies demonstrating that mice deficient in CHIP have pervasive dysfunction far more robust than would be predicted based on a primary role as a conventional E3 ligase. CHIP insufficiency results in decreased life expectancy and profound lipid oxidation, as well as poor performance on behavioral assessments of motor function and anxiety (McLaughlin et al., 2012; Palubinsky et al., 2015). Notably, CHIP KO animals are unable to complete even simple behavioral assessments given their moribund nature.

Mutations in CHIP have been identified in patients with an early-onset, recessive form of spinocerebellar ataxia, in which mutations in major structural domains confer loss of CHIP function (Heimdal et al., 2014; Shi et al., 2014; Synofzik et al., 2014; Bettencourt et al., 2015). Patients exhibit some unifying symptoms that include progressive deterioration in muscle coordination and tone, speech difficulty, and cerebellar atrophy. However, symptom heterogeneity exists among patients with CHIP mutations, which include dementia, hypogonadism, and epilepsy. Such variable observations support a role for CHIP beyond the cerebellum, where CHIP mutations can cause a multidimensional, multisystemic degenerative disease (Hayer et al., 2017).

In this work, we sought to understand the underpinnings of the devastating phenotype caused by loss of CHIP by evaluating its role in cell signaling using neuronal models of acute pathophysiological stress. Using a combination of cellular imaging, proteomics, biochemistry, molecular targeting, and ultrastructural assays, we determined that CHIP deficiency results in radical mitochondrial reorganization not seen in other E3 ligase-deficient animals. These data reinforce a model in which CHIP functions are more consistent with a role as an essential autophagy regulator than a standard E3 ligase. Together, our data support the use of these animals as a powerful and robust model of neurological dysfunction induced by mitochondrial failure and secondary proteotoxicity.

\section{Materials and Methods}

Materials and reagents

Tissue culture. FBS (SH30070.03) was obtained from Hyclone. DMEM (11995) with high-glucose minimum essential medium (MEM, 51200), Neurobasal medium, B27 supplement (17504044), N2 supplement

original CHIP KO animals; Ms. Sharon Klein, Ms. Arulita Gupta, and Ms. Dominique Szymkiewizz for technical assistance and ImageJ expertise; Dr. Joshua Fessel and Dr. Alice Soragni for electron microscopy expertise; Dr. Christopher E. Wright and Mr. Jeff Duryea for imaging assistance; Ms. Ama J. Winland for cell culture maintenance; and the Vanderbilt Cell Imaging Shared Resource for TEM preparation and imaging.

The authors declare no competing financial interests.

Correspondence should be addressed to BethAnn McLaughlin, Vanderbilt University Medical Center, 465 21st Avenue South, MRB III, Room 8110A, Nashville, TN 37232-8548. E-mail: bethann.mclaughlin@vanderbilt.edu.

DOI:10.1523/JNEUROSCI.0699-18.2018

Copyright $\odot 2018$ the authors $\quad 0270-6474 / 18 / 386826-16 \$ 15.00 / 0$
(17502048), 0.25\% Trypsin-EDTA, Trypan blue stain $0.4 \%$, and penicillin-streptomycin (15140-122) were from Invitrogen. The LipoJet In Vitro Transfection Kit (Ver. II) was from SignaGen.

Western blotting. XT-MOPS running buffer, Tris-glycine transfer buffer, Criterion Bis-Tris gels, Laemmli buffer, and precision plus protein all blue standards were from Bio-Rad Laboratories. Membrane-blocking solution was from Zymed. Hybond P polyvinylidene difluoride membranes were from GE Healthcare. Gel Code Blue Stain Reagent and Western Lightning Chemiluminescence Reagent Plus were from Thermo Scientific.

For Western blotting, CHIP (PC711, RRID:AB_2198058) antibody was from Calbiochem. Antibody for p62 was from Cell Signaling Technology (5114). LC3 for Western blotting was from MBL International (PD014, RRID:AB_843283) and, for immunofluorescence, LC3 was from Abcam (ab62116, RRID:AB_2281379). HSP70/HSP72 (SPA-811, RRID:AB_2120896), and HSC70 antibodies (SPA-816, RRID:AB_312224) were from Enzo Life Science. PINK1 (BC100-494, RRID:AB_10127658) and TOM20 (H00009804-M01, RRID:AB_2303717) antibodies were from Novus Biologicals. CHIP (sc-133066, RRID:AB_2286870) antibody for immunofluorescence was from Santa Cruz Biotechnology.

Unless otherwise stated, all other chemicals were from Sigma-Aldrich.

\section{Experimental design and statistical analysis}

Statistical analyses were performed using GraphPad Prism version 5.03 (RRID:RRID:SCR_002798). Error bars indicate SEM and statistical significance was assessed by one-way ANOVA followed by Bonferroni post hoc analysis (see Figs. 1C, 3A, 7A and Tables 1, 2, 3), paired two-tailed Student's $t$ test (see Table 4), unpaired two-tailed Student's $t$ test (see Figs. $1 E, 2 D, 4 E, 5 A, 6 B, 7 B, C$ ), Mann-Whitney analysis (see Fig. $4 F$ ), or two-way ANOVA (see Fig. $5 B$ ). Experimental replicates labeled as " $n$ " were derived from at least three independent cell cultures or animals as indicated and are described further in each Materials and Methods section. Significance is reported in the Results section and full statistical results are detailed in the figure legends.

\section{Maintenance of CHIP WT and KO mouse colony}

The Institutional Animal Care and Use Committee at Vanderbilt University Medical Center approved all animal husbandry and experiments. Parental mouse lines were described previously (Dai et al., 2003). All mice were maintained on a mixed background of C57BL/6 and $129 \mathrm{SvEv}$ for eight or nine generations. Further backcrossing exacerbates the early lethality observed in CHIP KO animals, resulting in a $<5 \%$ survival at birth. Because CHIP KO male mice are sterile, heterozygous matings were used to maintain the colony. Generating CHIP KO animals from heterozygous crossings occurs at non-Mendelian rates because of preferential reabsorption and cannibalism of $\mathrm{KO}$ animals that are often runted. Genotyping was performed by PCR with DNA from tail clippings using primers for the CHIP allele. Primers were from XXIDT and the sequences of the reverse and forward primers used were as follows: 5' TGA CAC TCC TCC AGT TCC CTG AG 3' and 5' AAT CCA CGA GGC TCC GCC TTT 3', respectively.

\section{Rat primary neuronal culture}

Forebrain cultures were prepared from embryonic day 18.5 (E18.5) Sprague Dawley rats as described previously (Stankowski et al., 2011). Briefly, forebrain was dissociated and the resultant cell suspension was adjusted to 750,000 cells/well in six-well tissue culture plates containing five, $12 \mathrm{~mm}$ poly-L-ornithine-treated coverslips/well. Plating media was composed of 84\% (v/v) Dulbecco's modified MEM, 8\% (v/v) Ham's F12 nutrients, $8 \%$ (v/v) FBS, $24 \mathrm{U} / \mathrm{ml}$ penicillin, $24 \mu \mathrm{g} / \mathrm{ml}$ streptomycin, and $80 \mu \mathrm{M}$ L-glutamine.

Cultures were maintained at $37^{\circ} \mathrm{C}, 5 \% \mathrm{CO}_{2}$, and media were partially replaced every $2-3 \mathrm{~d}$. Glial cell proliferation was inhibited after $2 \mathrm{~d}$ in culture with $2 \mu \mathrm{M}$ cytosine arabinoside and cells were maintained thereafter in Neurobasal medium supplemented with 2\% B27 and 2\% NS21 until $17 \mathrm{~d}$ in vitro (DIV) (Chen et al., 2008). B27 was then removed from the feeding medium and cultures were maintained in Neurobasal medium supplemented with NS21 only. This preparation yields a $98 \%$ neuronal culture with a mature complement of NMDA receptors (Zeiger et al., 2010). All experiments were conducted between DIV 20 and 27. 


\section{Neuronal bioenergetic stress}

Neurons were exposed to brief periods of bioenergetic stress by removing oxygen and glucose to trigger mitochondrial stress signaling. Oxygenand-glucose deprivation (OGD) was performed as described previously (Palubinsky et al., 2015) with minor modifications. Briefly, a complete media exchange was performed by transferring coverslips into wells containing deoxygenated, glucose-free Earle's balanced salt solution containing $150 \mathrm{~mm} \mathrm{NaCl}, 2.8 \mathrm{~mm} \mathrm{KCl}, 1 \mathrm{~mm} \mathrm{CaCl}_{2}$, and $10 \mathrm{~mm} \mathrm{HEPES,} \mathrm{pH}$ 7.3. Cultures were placed in an anaerobic chamber (Billups-Rothberg) for various durations $(15-90 \mathrm{~min})$ at $37^{\circ} \mathrm{C}$. OGD was terminated by moving coverslips into 6- or 24-well plates containing MEM, 0.01\% $(\mathrm{w} / \mathrm{v})$ BSA, $2.5 \%(\mathrm{v} / \mathrm{v})$ HEPES, and $2 \times \mathrm{N} 2$ (MEM/BSA/HEPES/N2). After $18-24 \mathrm{~h}$, neuronal viability was assessed visually and via $\mathrm{LDH}$ assays.

\section{Viability assay of rat primary neurons}

Cell viability was assessed using an LDH-based in vitro toxicity kit (Sigma-Aldrich) that colorimetrically determines the amount of LDH released into the culture media from dead and dying neurons.

To account for variation in total $\mathrm{LDH}$ content, raw $\mathrm{LDH}$ values were normalized to the toxicity caused by $90 \mathrm{~min}$ OGD, which, at $24 \mathrm{~h}$, results in $100 \%$ neuronal cell death in this system. Viability was also confirmed visually with corresponding bright-field images.

\section{Preconditioning and CHIP siRNA knock-down in rat primary neurons}

Primary neuronal cultures were grown for $20-25 \mathrm{~d}$ in vitro, after which they were exposed to low-level bioenergetic stress (15 min OGD) and immediately returned to normoxia in MEM/HEPES/BSA/N2 medium. For studies of mitophagy, neurons were incubated in bafilomycin A1 (BafA; $1 \mathrm{nm)} 30$ min before, during, and after OGD. Twenty-four hours after preconditioning, neurons were exposed to 90 min of OGD and viability was determined $24 \mathrm{~h}$ later using LDH assays and visual confirmation.

CHIP small interfering RNA (siRNA) was obtained from QIAGEN (50-CCAGCTGGAGATGGA GAGTTA-30) (Stankowski et al., 2011). Using the LipoJet Transfection Kit, CHIP siRNA (25 nM) and green fluorescent protein (GFP; $2 \mu \mathrm{g}$ ) were added dropwise into each well of a 6 -well dish containing neurons in $2 \mathrm{ml}$ of growth medium. Six hours after addition of transfection reagents, cells underwent a complete medium change. CHIP siRNA-transfected cells were harvested $24-72 \mathrm{~h}$ after transfection in TNEB lysis buffer containing the following: $50 \mathrm{~mm}$ TrisCl, pH 7.8, 2 mм EDTA, $150 \mathrm{~mm} \mathrm{NaCl,} 8$ m $\beta$-glycerophosphate, 100 $\mu \mathrm{M}$ sodium orthovanadate, $1 \%[\mathrm{v} / \mathrm{v}$ ] Triton X-100, and protease inhibitor (P8340) diluted 1:1000, and extracts were prepared for Western blotting. Pilot experiments revealed optimal knockdown of CHIP expression at $24 \mathrm{~h}$ (see Fig. $5 \mathrm{~A}$ ) and this time point was used for all subsequent studies of acute CHIP knock-down.

\section{Western blotting of primary neuronal lysate}

For in vitro lysates, all cell lysis and harvesting steps took place on ice. Cells were washed twice with ice-cold $1 \times$ PBS and after the second wash, $150-400 \mu \mathrm{l}$ of TNEB lysis buffer was added.

Approximately 100-200 $\mu$ l of lysate was resuspended in an equal volume of Laemmli buffer with $\beta$-mercaptoethanol (1:20). Protein samples were heated to $95^{\circ} \mathrm{C}$ for $10 \mathrm{~min}$ and stored at $-20^{\circ} \mathrm{C}$. Equal protein concentrations were determined by DC Protein Assay Kit II and samples were separated on $4-12 \%$ Criterion Bis-Tris gels. Proteins were transferred to PVDF membranes and blocked in methanol for $5 \mathrm{~min}$. After 10 min of drying, the membranes were incubated overnight with antibodies detecting CHIP, HSP70, HSC70, TOM20, p62, PINK1, or LC3 in 5\% nonfat dry milk in TBS-Tween $(0.1 \%)$ or in membrane blocking solution at $4^{\circ} \mathrm{C}$. Membranes were washed three times with TBS-Tween and incubated with horseradish peroxidase conjugated secondary antibodies for $1 \mathrm{~h}$ at room temperature (RT). After three washes in TBS-Tween, protein bands were visualized using Western Lightning chemiluminescence plus enhanced luminol reagent. Western blots were analyzed using ImageJ (RRID:SCR_002285) to determine the mean relative densities of each protein band and fold changes were calculated using untreated cultures as controls. Data represent results from at least three independent experiments as indicated in the figure legends.

\section{CHIP WT and KO mouse primary neuronal culture}

Forebrain cultures were prepared from E18 mice generated by heterozygous matings as described previously (Palubinsky et al., 2015). Briefly, mice were decapitated and the entire brain was stored individually in Hibernate E medium (HE-Pr; Brain Bits) at $4^{\circ} \mathrm{C}$ and tails were processed for genotyping. Once PCR was concluded, WT and KO brains were pooled by genotype and dissection continued with cortical tissue digestion in $0.025 \%$ trypsin for $20 \mathrm{~min}$, followed by mechanical dissociation. Resultant cell suspensions were plated at 600,000 cells $/ \mathrm{ml}$.

Cultures were maintained at $37^{\circ} \mathrm{C}, 5 \% \mathrm{CO}_{2}$ in growth medium comprising a volume-to-volume mixture of $84 \%(\mathrm{v} / \mathrm{v})$ DMEM, $8 \%(\mathrm{v} / \mathrm{v})$ Ham's F12-nutrients, $8 \%$ (v/v) FBS, $24 \mathrm{U} / \mathrm{ml}$ penicillin, $24 \mu \mathrm{g} / \mathrm{ml}$ streptomycin, and $80 \mu \mathrm{M}$ L-glutamine. Before plating, $2 \times \mathrm{N} 2$ and $2 \% \mathrm{NS} 21$ $(\mathrm{v} / \mathrm{v})$ supplements were added to the growth medium. Glial proliferation was inhibited after $2 \mathrm{~d}$ in culture via the addition of $2 \mu \mathrm{M}$ cytosine arabinoside, after which cultures were maintained in Neurobasal medium containing 2\% B27 (v/v), $2 \times \mathrm{N} 2$, and 2\% NS21 (v/v) supplements with antibiotics for 2 weeks. One week before experiments, neurons were maintained in Neurobasal medium containing 2\% (v/v) NS21 and antibiotics only. All experiments were conducted 20-25 d after dissociation.

\section{CHIP plasmid design and transfection}

Plasmids were generated by and obtained from ProNovus Bioscience. Mammalian expression vectors for nonmutated CHIP driven by a human promoter (hCHIP), TPR mutant hCHIP (K30A), and Ubox mutant hCHIP (H260Q) are based on pcDNA3.1 (Qian et al., 2006). The human CHIP promoter sequence was used to induce CHIP expression by endogenous transcription factors. For detection by immunofluorescence, an mCherry expression sequence was added to the $3^{\prime}$ end of the CHIP sequence using a $3 \times$ GGGGS linker. Using the LipoJet Transfection Kit, plasmid $(5 \mu \mathrm{g})$ was added dropwise into each well of a 6-well dish containing neurons in $2 \mathrm{ml}$ of growth medium. Six hours after transfection, cells underwent a complete medium change and experiments were performed the following day.

\section{Immunofluorescence of primary neurons}

Cells were fixed in $4 \%$ paraformaldehyde (PFA) and then permeabilized with $0.1 \%$ Triton X-100 as described previously (Palubinsky et al., 2015). Primary antibody was diluted in $1 \%$ BSA overnight at $4^{\circ} \mathrm{C}$. Cells were washed with $1 \times$ PBS for a total of $30 \mathrm{~min}$ and incubated in Cy-2, Cy-3, or Alexa Fluor 350 secondary antibodies (1:500) for $60 \mathrm{~min}$ at RT. Cells were counterstained with 4,6-diamidino-2-phenylindole (DAPI) to observe nuclei. Coverslips were mounted on glass slides using ProLong Gold (Fisher Scientific; P3693) and fluorescence was observed with a Zeiss Axioplan microscope at $63 \times$ or $40 \times$, as indicated.

\section{Cell counting and colocalization of immunofluorescent primary neurons}

Cell counts of primary neuronal cultures prepared for immunofluorescence staining of PINK1 and MAP2 and of CHIP and MAP2 were performed using ImageJ Fiji version 2.0.0-rc-43/1.50e (RRID:SCR_002285). Cell counts were performed by two blinded investigators. Statistical significance was determined by two-tailed unpaired $t$ test with $p<0.05$ using GraphPad Prism software.

Colocalization analysis of mouse primary neurons stained with CHIP and TOM 20 were performed using Coloc 2 in Fiji. Twenty to 30 fields per condition were chosen at random and measured by blinded investigators. Background was accounted for by using a Rolling-Ball Background Subtraction of 50. Neurons were outlined using the polygon drawing tool. Point spread function was calculated and set to 1.0 and Costes randomizations were set to 10 .

\section{Generation of WT and CHIP KO mouse embryonic fibroblast} (MEF) cultures

Fibroblast cell lines were developed based on previous protocols $(\mathrm{Xu}$, 2005). Briefly, E13 mouse pups generated by heterozygous matings were decapitated and internal organs were removed. Tail samples were taken 
and all remaining epidermal tissue was minced and placed in individual conical tubes containing $2 \mathrm{ml}$ of $0.25 \%$ trypsin-EDTA and digested at $4^{\circ} \mathrm{C}$ for $18 \mathrm{~h}$, followed by $30 \mathrm{~min}$ at $37^{\circ} \mathrm{C}$. Meanwhile, tails were processed for genotyping (Palubinsky et al., 2015). Once PCR and digestion were concluded, WT and $\mathrm{KO}$ tissue was pooled, an equal volume of MEF medium containing 84\% (v/v) DMEM, 10\% (v/v) FBS, $24 \mathrm{U} / \mathrm{ml}$ penicillin, and 24 $\mathrm{mg} / \mathrm{ml}$ streptomycin was added and the tissue was mechanically dissociated using a $5 \mathrm{ml}$ pipette, triturating $\sim 20$ times. Any remaining tissue was allowed to settle while the supernatant was transferred to a new tube. Five milliliters of MEF medium was added to the tissue pellet, trituration was repeated, and supernatant was collected and added to the initial cell suspension. Trituration and transfer were repeated a final time and the entire resultant cell suspension was plated in a T75 flask and maintained at $37^{\circ} \mathrm{C}$ and $5 \% \mathrm{CO}_{2}$ until cells reached $85 \%$ confluency, at which point they were passaged. Immortalization was achieved via repeated passaging $(\sim 25$ passages). After immortalization, all experiments were performed using MEFs between passages 10 and 20.

\section{Transmission electron microscopy (TEM) of MEFs}

WT and CHIP KO MEFs were grown to $60-80 \%$ confluency and fixed in $2.5 \%$ glutaraldehyde with $0.1 \mathrm{~m}$ cacodylate buffer, $\mathrm{pH} 7.4$, at RT and then transferred to $4^{\circ} \mathrm{C}$ overnight. Samples were further processed in the Vanderbilt University Medical Center Cell Imaging Shared Resource. Cells were washed, scraped, pelleted, and underwent several exchanges of fixative and dehydrating solvents. Samples were fixed in $2.5 \%$ gluteraldehyde in $0.1 \mathrm{~m}$ cacodylate buffer, $\mathrm{pH} 7.4$, at RT for $1 \mathrm{~h}$ and then transferred to $4^{\circ} \mathrm{C}$ overnight. The samples were washed in $0.1 \mathrm{M}$ cacodylate buffer, incubated $1 \mathrm{~h}$ in $1 \%$ osmium tetraoxide at RT, and then washed with $0.1 \mathrm{M}$ cacodylate buffer. Subsequently, the samples were dehydrated through a graded ethanol series and then three exchanges of $100 \%$ ethanol. Next, the samples were incubated for $5 \mathrm{~min}$ in 100\% ethanol and propylene oxide (PO) followed by 2 exchanges of pure PO. Samples were then infiltrated with 25\% Epon 812 resin and $75 \%$ PO for 30 min at RT. Next, they were infiltrated with Epon 812 resin and PO (1:1) for $1 \mathrm{~h}$ at RT and then overnight at RT. The next day, samples went through a $(3: 1$ resin: $\mathrm{PO}$ ) exchange for $3-4 \mathrm{~h}$ and then incubated with pure epoxy resin overnight. Samples were then incubated in two more changes of pure epoxy resin and allowed to polymerize at $60^{\circ} \mathrm{C}$ for $48 \mathrm{~h}$. Thin sections $(70-80 \mathrm{~nm})$ were cut using an ultramicrotome and mounted onto copper grids. The sections were stained with $2 \%$ uranyl acetate and Reynold's lead citrate before imaging at $26,000 \times$ and $67,000 \times$ on an electron microscope (Philips T12 equipped with an FEI AMT CCD camera system).

\section{MitoTracker labeling and immunofluorescence of MEFs}

WT and CHIP KO MEFs were grown to $60-80 \%$ confluency on glass coverslips. MitoTracker Orange staining was performed as described previously (Palubinsky et al., 2015). Briefly, MitoTracker (Fisher M7511) was added to live cell cultures at a final concentration of $790 \mathrm{~nm}$ and incubated at $37^{\circ} \mathrm{C}$ for $45 \mathrm{~min}$. Coverslips were washed with $1 \times \mathrm{PBS}$, fixed with $4 \%(\mathrm{v} / \mathrm{v})$ PFA, permeabilized with $0.1 \%$ Triton X-100, washed again with $1 \times$ PBS, and then blocked with $8 \%(\mathrm{w} / \mathrm{v})$ BSA diluted in $1 \times$ PBS. After $25 \mathrm{~min}$ in BSA, coverslips were incubated overnight at $4^{\circ} \mathrm{C}$ in primary antibody against $\beta$-tubulin diluted in $1 \%(\mathrm{w} / \mathrm{v})$ BSA. After primary antibody incubation, cells were washed with $1 \times$ PBS for a total of $30 \mathrm{~min}$ and incubated in Alexa Fluor 350 secondary antibody in 1\% BSA for $1 \mathrm{~h}$. Cells were next washed for a total of $30 \mathrm{~min}$ in $1 \times$ PBS and coverslips were mounted using Prolong Gold.

Using ImageJ Fiji, a total of 120 WT MEF cells and 169 CHIP KO MEF cells from two individual cultures were analyzed. Images were thresholded using an adaptive algorithm and particles were analyzed for total count, area, and perimeter. Area and perimeter values were then used to calculate mitochondrial circularity as follows: circularity $=4 \pi$ (area/ perimeter ${ }^{2}$ ), where values closer to 0 are less circular (i.e., ellipses, crescents, and complex tubular structures) and values close to 1 are perfectly circular.

\section{Proteomic analysis of WT and CHIP KO brains}

Tissue preparation and precipitation. Whole brains from postnatal day 35 WT mice (four male, four female) and CHIP KO mice (four male, four female) were removed and immediately placed into a glass Dounce ho- mogenizer containing $1 \mathrm{ml}$ of ice-cold TNEB lysis buffer. Brains were homogenized on ice ( 35 strokes), sonicated at $6 \mathrm{~W}$ for $10 \mathrm{~s}$, and passed through a $40 \mu \mathrm{m}$ cell strainer then through a $0.2 \mu \mathrm{m}$ filter affixed to a 10 $\mathrm{ml}$ syringe. Protein assays were completed and all samples were adjusted to $2 \mathrm{mg}$ in $1 \mathrm{ml}$ of TNEB. Samples were precipitated by adding $3 \mathrm{ml}$ of ice-cold ethanol, vortexing, and incubating on ice for $3 \mathrm{~min}$. After incubation, samples were spun at $3000 \times \mathrm{rpm}(1819 \times \mathrm{g})$ for $10 \mathrm{~min}$ at $4^{\circ} \mathrm{C}$. Upon removal of the supernatant, pellets were incubated in a 2:1 mixture of chloroform and ice-cold methanol for $3 \mathrm{~min}$ and centrifuged at $3000 \times \mathrm{rpm}(1819 \times \mathrm{g})$ for $10 \mathrm{~min}$. After centrifugation, pellets were washed 3 times in $1 \mathrm{ml}$ of ice-cold methanol. After the third wash, pellets were resuspended in $1 \mathrm{ml}$ of $0.5 \%$ SDS and sonicated at $6 \mathrm{~W}$ for 10 pulses. After sonication, $10 \mu \mathrm{l}$ of sample was added to $8 \mu \mathrm{l}$ of $4 \times$ sample buffer and $2 \mu \mathrm{l}$ of $1 \mathrm{M}$ DTT. This portion of the sample was heat denatured at $95^{\circ} \mathrm{C}$ for $10 \mathrm{~min}$ and the rest of the sample was used for a protein assay.

Peptide preparation. Peptides were prepared as described previously (Ham, 2005). Briefly, equal protein amounts of each sample were loaded onto a $10 \%$ Bis-Tris gel with empty lanes in between samples and separated at $180 \mathrm{~V}$ for $30 \mathrm{~min}$. Simply Blue Safe Stain was used to visualize all protein bands to allow for each sample to be cut horizontally into $\sim 13$ fractions. Each horizontal fraction was then cut vertically into $\sim 1 \mathrm{~mm}$ cubes and placed in a microcentrifuge tube. One hundred microliters of $100 \mathrm{~mm}$ ammonium bicarbonate (AmBic) was added to each fraction tube.

Samples were reduced with $5 \mathrm{~mm}$ DTT in AmBic for $30 \mathrm{~min}$ at $60^{\circ} \mathrm{C}$ with shaking. Samples were then alkylated with $10 \mathrm{~mm}$ iodoacetamide in AmBic for $20 \mathrm{~min}$ in the dark at RT. Any remaining Safe Stain dye was removed with additional $100 \mu \mathrm{l}$ washes in $50 \mathrm{~mm}$ AmBic /acetonitrile $(1: 1, v / v)$. Once clear of all dye, gel pieces were dehydrated in $100 \%$ acetonitrile. Next, samples were rehydrated in $200 \mu \mathrm{l}$ of $25 \mathrm{~mm}$ AmBic containing $300 \mathrm{ng}$ of trypsin gold (Promega) and incubated at $37^{\circ} \mathrm{C}$ overnight. After trypsinization, peptides were extracted from the gel via 3 $20 \mathrm{~min}$ washes in $200 \mu \mathrm{l}$ of $60 \%$ aqueous acetonitrile containing $1 \%$ formic acid and evaporated to dryness in vacuo. Last, peptides were resuspended in $30 \%$ aqueous acetonitrile containing $0.1 \%$ formic acid and stored at $-80^{\circ} \mathrm{C}$ (Ham, 2005).

Mass spectrometry. Protein digests were lyophilized and resuspended in water before solid phase extraction with a Waters Oasis HLB cartridge. Before use, cartridges were activated with $1 \mathrm{ml}$ of acetonitrile and equilibrated with $2 \mathrm{ml}$ of water. Peptides were loaded, washed once with $1 \mathrm{ml}$ of water, and eluted with $70 \%$ acetonitrile containing $0.1 \%$ formic acid. Peptides were evaporated to dryness in vacuo, resuspended in $10 \mathrm{~mm}$ triethylammonium bicarbonate, $\mathrm{pH}$ 8.0, and fractionated by bRPLC on an Agilent 1260 Infinity LC system equipped with an XBridge C18 $5 \mu \mathrm{m}$ $4.6 \times 250 \mathrm{~mm}$ column. Solvent A was aqueous $10 \mathrm{~mm}$ triethylammonium bicarbonate at $\mathrm{pH} 7.4$ and solvent $\mathrm{B}$ was $10 \mathrm{~mm}$ triethylammonium bicarbonate in acetonitrile at a flow rate of $0.5 \mathrm{ml} / \mathrm{min}$.

Peptides were further fractionated by a gradient in which solvent $B$ was increased from $0 \%$ to $5 \%$ from 0 to $10 \mathrm{~min}, 5 \%$ to $35 \%$ from 10 to $70 \mathrm{~min}$, $35 \%$ to $70 \%$ from 70 to $85 \mathrm{~min}$, held at $70 \%$ from 85 to $95 \mathrm{~min}$, and reduced to $0 \%$ from 95 to $105 \mathrm{~min}$. The eluted peptides were collected in 64 fractions, which were concatenated to 15 fractions as described previously (Wang et al., 2011b). Concatenated fractions were evaporated to dryness in vacuo and dried samples were resuspended in $100 \mu \mathrm{l}$ of $3 \%$ acetonitrile with $0.1 \%$ formic acid for LC-MS/MS analysis.

LC-MS/MS analyses were performed on a Q Exactive Plus mass spectrometer (Thermo Fisher Scientific) equipped with a Proxeon nLC1000 LC (Thermo Fisher Scientific) and a Nanoflex source (Thermo Fisher Scientific). Peptides were resolved on an 11-cm-long column with a 75 $\mu \mathrm{m}$ internal diameter (New Objective PF360-75-10-N-5) packed with 3 $\mu \mathrm{m}$ particle size and $120 \AA$ pore size ReproSil-Pur C18-AQ resin (Dr. Maisch GmbH, Ammerbuch-Entringen, Germany) over a 70 min gradient at a $300 \mathrm{nl} / \mathrm{min}$ flow rate. The gradient was formed using $0.1 \%$ formic acid in water (solvent $\mathrm{A}$ ) and $0.1 \%$ formic acid in acetonitrile (solvent $\mathrm{B}$ ); the percentage of B was varied as follows: $2 \%$ to $5 \%$ in $5 \mathrm{~min}, 5 \%$ to $35 \%$ over $55 \mathrm{~min}, 35 \%$ to $90 \%$ in $3 \mathrm{~min}$, followed by $90 \%$ for $7 \mathrm{~min}$.

A single MS1 scan from m/z 300-1800 at 70,000 resolution with an automatic gain control (AGC) value of $3 \mathrm{e} 6$ and max injection time of 64 ms was recorded as profile data. A top 12 method was used in which the 
12 most intense precursors were automatically chosen for MS2 analysis and a dynamic exclusion window of $20 \mathrm{~s}$ was used. For each MS2 scan, a resolution of 17,500, an AGC value of 2e5, a max injection time of 100 $\mathrm{ms}$, a $2.0 \mathrm{~m} / \mathrm{z}$ isolation window, and a normalized collision energy of 27 was used and centroid data were recorded.

Thermo ".raw" datafiles from LC-MS/MS runs were converted to ".mzml" format using Proteowizard version 3.0.5211 (Kessner et al., 2008). The .mzml files were searched using MyriMatch version 2.1.132 (Tabb et al., 2007) and MS-GF+ version 9517 (Kim and Pevzner, 2014) against the mouse Refseq database (October 16, 2014). A semitryptic search was used with a maximum of four missed cleavages allowed. A fixed carbimidomethyl modification on Cys, a variable oxidation on Met, and a pyro-glu on Gln were allowed with a maximum of two dynamic modifications per peptide. Precursor ions were required to be within 15 ppm of expected values and fragment ions within $20 \mathrm{ppm}$. A target decoy search was used using a reverse sequence database to allow calculation of FDR for peptide spectral matches. The final protein list was assembled following the rule of parsimony in IDPicker 3 version 3.1.643.0 (Ma et al., 2009 ) at a protein FDR of $<1 \%$. This protein list was then analyzed for spectra, which were found to have a twofold or greater different between WT and KO CHIP mice.

\section{Results}

Low-level bioenergetic stress induces CHIP expression

In neuron-enriched cultures, bioenergetic stress induced by 15 min of OGD initiates a robust defensive program with sufficient magnitude to significantly decrease the cell death associated with a subsequent exposure to a normally lethal $90 \mathrm{~min}$ period of OGD (Fig. 1A). Consistent with prior reports, both bright-field photomicrographs of live cells (Fig. 1B) and LDH release assays (Fig. $1 C$ ) reveal that low-level bioenergetic stress protects $\sim 45 \%$ of neurons from subsequent injury (McLaughlin et al., 2003; Brown et al., 2010; Zeiger et al., 2010). Importantly, this stressor does not result in neuronal cell death, as evident by phase-bright somas and intricate processes that are indistinguishable from control cells (Fig. 1B). To examine the temporal and spatial time course of CHIP expression in cells primed with by low-level bioenergetic event, we harvested neurons at various time points after $15 \mathrm{~min}$ of OGD. CHIP expression begins to increase within $1 \mathrm{~h}(1.8 \pm 0.4$-fold above control, Table 1$)$, peaks $6 \mathrm{~h}$ after stress $(2.8 \pm 0.8$-fold above control) and remains elevated at $24 \mathrm{~h}(1.7 \pm 0.3$-fold above control; Fig. 1D). Increases in HSP70 expression lag behind CHIP, peaking between 6 and $18 \mathrm{~h}(2.5 \pm 0.2$-fold above control; Fig. $1 D)$ and returning to baseline levels at $24 \mathrm{~h}(0.9 \pm 0.4$-fold of control; Fig. 1D).

To determine the percentage of neurons that express CHIP in response to bioenergetic stress, we stained neurons $24 \mathrm{~h}$ after 15 min OGD. Although we observed an increase in total CHIP expression via Western blot, using immunocytochemistry (ICC), we observed that CHIP is expressed in $49 \%$ of mildly stressed neurons, which was not significantly different from control cultures (Fig. 1E). Given that CHIP expression undergoes temporal and spatial changes in response to stress (Fig. 1C; (Stankowski et al., 2011; Palubinsky et al., 2015), we suspect that using this method failed to capture the dynamic turnover and subcellular localization of CHIP at a static time point of $24 \mathrm{~h}$ after OGD.

In previous work, mitochondria isolated from CHIP KO animals exhibited dysfunction in response to calcium challenge, suggesting that CHIP is important for mitochondrial homeostasis during stress (Palubinsky et al., 2015). To test this hypothesis, we used the mitochondrial import receptor TOM20 to label mitochondria and costained for CHIP in cells exposed to bioenergetic stress. We observed increased overlap of CHIP with TOM20positive mitochondria as early as $3 \mathrm{~h}$ after acute stress (data not shown) that was maximal at $6 \mathrm{~h}$ (Fig. $1 \mathrm{~F}$, overlap of CHIP and
TOM20 are shown in white). Together, these data demonstrate that CHIP localizes to mitochondria during the period in which neurons are upregulating endogenous protective pathways and HSP70. We next sought to determine how mitochondrial quality control signaling is affected by low-level bioenergetic stressors.

\section{Low-level bioenergetic stress changes mitochondrial morphology and increases expression of the mitophagy-related protein PINK1}

Mitochondria are dynamic organelles that undergo continuous fission and fusion events, as well as mitophagy. All of these processes are induced by various cell stressors, including mild hypoxic stress (Archer, 2013). To determine the morphology of mitochondria during low-level bioenergetic stress, rat primary neurons were exposed to $15 \mathrm{~min}$ of OGD and then visualized with TOM20 immunostaining $24 \mathrm{~h}$ later.

We found that, although control and mildly stressed neurons exhibit healthy, structurally similar processes and nuclei based on MAP2 and DAPI fluorescence, mitochondrial localization is profoundly affected by bioenergetic status (Fig. 2A). Mitochondria are typically well dispersed within the soma and along processes. However, low-level stress increased the number of fragmented mitochondria along neuronal processes and clustering of mitochondria within the soma.

During cell stress, mitochondrial membrane potential is compromised, allowing retention and accumulation of PINK1 on the outer mitochondrial membrane (Greene et al., 2012; Jin and Youle, 2013). The kinase activity of PINK1 recruits E3 ligases, such as Parkin, as well as the autophagy protein LC3, which seeds formation of an autophagosome around the mitochondrion (Kawajiri et al., 2010; Klionsky et al., 2016).

We hypothesized that stabilization of PINK1 and mitochondrial clearance may participate in neuroprotection by priming neurons for a secondary stress. To test this hypothesis, whole-cell lysate was collected 3, 6, and $24 \mathrm{~h}$ after bioenergetic stress and full-length, stabilized PINK1 was found to rapidly increase and remain elevated for $24 \mathrm{~h}(3.3 \pm 2.1$-fold above control; Fig. $2 B$, Table 2).

To further elucidate the extent of bioenergetically induced PINK1 stabilization in neurons, we stained for PINK1 $24 \mathrm{~h}$ after $15 \mathrm{~min}$ of OGD and found a significant increase in the total number of PINK1-positive cells compared with untreated cultures (28\% increase; Fig. 2C,D). The number of MAP2-positive neurons does not change after PC, consistent with previous data (Fig. 1); however, we observe that the underlying neuropil undergoes remodeling that is made apparent using immunofluorescence techniques (Fig. 2C). Given that PINK1 is a rapid sensor of mitochondrial dysfunction, these data are consistent with our prior observation that although 15 min of OGD is a mild bioenergetic stress resulting in no neuronal cell death (Fig. 1B,C), it does cause substantive energetic and oxidative stress (Stankowski et al., 2011).

\section{Autophagic signaling is required for achieving a protective response}

Some E3 ligases, such as Parkin, play critical roles in promoting mitophagy in response to stress, but likely not in the normal clearance of these organelles (Kubli et al., 2013). We therefore sought to determine the role of CHIP in both pathophysiological and physiological mitophagy in neurons.

To determine the contribution of mitophagy, we used the autophagy inhibitor, BafA, to prevent lysosome acidification during our mild bioenergetic stress (Klionsky et al., 2016). The next day, we treated rat primary neurons with 90 min of OGD, which is typically 


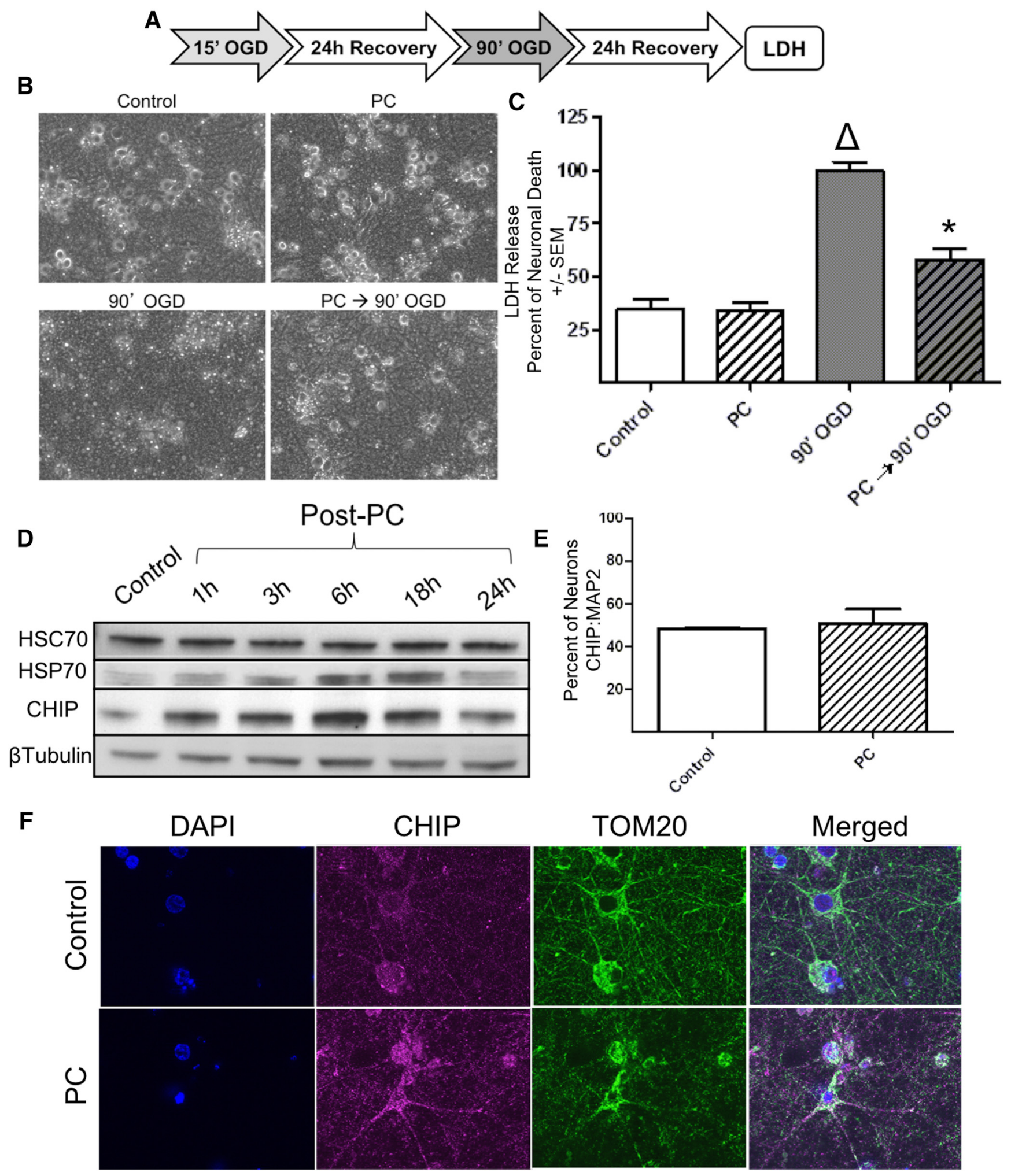

Figure 1. Low-level bioenergetic stress induces CHIP expression. A, Primary rat forebrain cultures were exposed to $15^{\prime} 0 G D$. Twenty-four hours later, neurons were exposed to $90^{\prime}$ OGD, after which cells were returned to growth media. Cell survival was assessed via LDH $24 \mathrm{~h}$ later. $\boldsymbol{B}$, Representative photomicrographs taken $24 \mathrm{~h}$ after $15^{\prime} 0 \mathrm{GD}$ (PC) reveal many phase-bright neuronal somas and intact processes that are indistinguishable from control. Twenty-four hours after $90^{\prime} O G D$, there were no phase-bright neurons, indicative of total neuronal death. Cultures that were preconditioned $\left(\mathrm{PC} \rightarrow 90^{\prime} \mathrm{OGD}\right.$ ) contained more phase-bright neurons and intact processes compared with $90^{\prime} 0 \mathrm{GD}$. C, LDH release was measured and values were normalized to $90^{\prime} 0 \mathrm{GD}$ ( $100 \%$ cell death) in naive cells. Data were analyzed by one-way ANOVA with Bonferroni post hoc testing $\left(R^{2}=0.7123, F=46.21, p<0.0001, n=4\right)$. $\Delta$ Statistical significance $(p<0.05)$ comparing $90^{\prime}$ $0 G D$ with control cultures. *Statistical significance comparing $\mathrm{PC} \rightarrow 90^{\prime}$ and all other groups $(p<0.05)$. $\boldsymbol{D}$, Neurons exposed to $15^{\prime}$ ' $0 \mathrm{GD}$ were harvested $1,3,6,18$, or $24 \mathrm{~h}$ later. Whole-cell lysates were probed with antibodies against HSP70 and CHIP, as well as HSC70 and $\beta$-Tubulin as loading controls. Quantification is summarized in Table 1.E, Twenty-four hours after PC, cultures were probed with antibodies to CHIP, MAP2, and DAPI. Cell counts were performed by blinded investigators. Basal CHIP expression is observed in 49\% of MAP2-positive neurons and is not significant from control after $\mathrm{PC}(t=0.367, \mathrm{df}=4, p=0.732, n=3$, Student's $t$ test). $\boldsymbol{F}$, Preconditioned neurons were PFA fixed after $6 \mathrm{~h}$ of recovery and probed for CHIP (magenta), TOM20 (green), and DAPI (blue). 
Table 1. Quantification of CHIP and HSP70 after mild bioenergetic stress

\begin{tabular}{lllllll}
\hline \multicolumn{7}{c}{ Fold change normalized to control } \\
\cline { 3 - 7 } & $n$ & $1 \mathrm{~h}$ & $3 \mathrm{~h}$ & $6 \mathrm{~h}$ & $18 \mathrm{~h}$ & $24 \mathrm{~h}$ \\
\hline HSC70 & 4 & $0.9 \pm 0.1$ & $0.9 \pm 0.2$ & $1.3 \pm 0.5$ & $1.0 \pm 0.3$ & $1.1 \pm 0.4$ \\
HSP70 & 4 & $1.4 \pm 0.4$ & $2.1 \pm 0.3$ & $2.5 \pm 0.2$ & $1.0 \pm 0.7$ & $1.3 \pm 0.3$ \\
CHIP & 4 & $1.8 \pm 0.4$ & $2.2 \pm 0.4$ & $2.8 \pm 0.8$ & $2.5 \pm 0.8$ & $1.7 \pm 0.3$ \\
$\beta$-Tubulin & 4 & $1.2 \pm 0.1$ & $1.3 \pm 0.1$ & $1.2 \pm 0.2$ & $1.2 \pm 0.2$ & $1.2 \pm 0.1$ \\
\hline
\end{tabular}

Neurons exposed to $15^{\prime}$ OGD were harvested $1,3,6,18$, or $24 \mathrm{~h}$ later. Whole-cell lysates were probed with antibodies against HSP70 and CHIP, with HSC70 and $\beta$-Tubulin as loading controls (Figure 1D). Bands were quantified by ImageJ Fiji densitometry analysis. Values summarized in the table are the average band intensity relative to control \pm SEM. Significance was determined using one-way ANOVA with Bonferroni's post hoc analysis. Increased HSP70 expression after mild bioenergetic stress was statistically significant at $6 \mathrm{~h}$ after $0 G D\left(R^{2}=0.520, F=3.897\right.$, $p=0.014)$. CHIP increased early after OGD and remained increased above control levels, although the differences were not statistically significant $\left(R^{2}=0.305, F=1.577, p=0.217\right)$. No significant differences were observed in loading controls HSC70 $\left(R^{2}=0.052, F=0.296, p=0.960\right)$ and $\beta$-Tubulin $\left(R^{2}=0.1255, F=0.517, p=0.760\right)$.

lethal, and assessed cell death $24 \mathrm{~h}$ later. Neurons treated with 1 nM BafA during the priming event exhibited increased cell death after secondary stress compared with those that only received the initial, mild bioenergetic priming stress $(p<0.05, n=4$; Fig. 3A).

By measuring CHIP and HSP70 expression in this paradigm, we determined that both proteins were highly expressed in primed neurons in the presence of BafA, with CHIP expression significantly increased by $24 \mathrm{~h}(1.4 \pm 0.1$-fold above control; Fig. $3 B$, Table 3). Although PINK1 increased after OGD in the presence or absence of BafA, this was not statistically different. To determine autophagic flux, we quantified Western blot band intensities of LC3-I and LC3-II (Klionsky et al., 2016) and observed that LC3-II accumulated in cultures preconditioned with BafA cotreatment, revealing impeded autophagic flux (LC3-II:LC3-I, $2.1 \pm 0.3$-fold above control; Fig. 3B, Table 3 ). We also observed dramatically increased accumulation of LC3- and CHIP-positive autophagosomes in neurons after low-level OGD (Fig. 3C, middle). This effect was further augmented with BafA treatment (Fig. $3 C$, right). Together, these data suggest that CHIP localization to mitochondria coincides with mitophagy and that mitophagy is a critical component of the neuroprotection afforded by preconditioning.

\section{CHIP deficiency increases mitochondrial number and changes mitochondrial morphology}

Given the increased CHIP localization to mitochondria during mild bioenergetic stress, we sought to determine whether CHIP also played a role in mitochondrial homeostasis during physiological conditions. MEFs provide higher-resolution imaging of mitochondrial morphology than neurons because they are large, flat, and nonpolarized. We hypothesize that changes in mitochondrial morphology caused by CHIP loss are pervasive and will manifest even in mitotic, peripheral cell types.

WT and CHIP KO MEFs were prepared for TEM after 15-20 passages under normal growth conditions where both cell lines underwent mitosis after $\sim 30 \mathrm{~h}$. TEM imaging of WT MEFs revealed large, round mitochondria with intact membranes and many thin cristae (Fig. 4A-C). These cells contain large lysosomes and the endoplasmic reticuli appear tubular throughout the slice. CHIP KO MEFs were appreciably different from WT cells in that the majority of mitochondria had thick, swollen cristae and smaller matrices (Fig. 4D-F), which is consistent with mitochondrial stress and swelling even though the cells proliferated normally. $\mathrm{KO}$ MEFs also contained fewer lysosomes and irregularly shaped endoplasmic reticuli.

To quantify the extent of mitochondrial morphological changes, we performed MitoTracker Orange staining in WT and CHIP KO MEFs and prepared them for ICC with $\beta$-tubulin costain. Using
ImageJ Fiji, we quantified mitochondrial number, area, and perimeter. Area and perimeter values were then used to calculate mitochondrial circularity, where values closer to 0 are less circular (i.e., more tubular) and values close to 1 are perfectly circular.

CHIP KO MEFs contained significantly greater numbers of mitochondria than WT (Fig. 4G). Given the large amount of variability in CHIP $\mathrm{KO}$ mitochondrial number (WT: mean = 640, SEM $=33.43$; KO: mean $=1307$, SEM = 63.96), we hypothesize that, during the division phases of mitosis, CHIP KO fibroblasts undergo bioenergetic, mitophaghic and proteostatic pressures that result in highly variable mitochondria that are not observed in normal fibroblasts. These data are consistent with previous reports that mitochondrial mass is largely affected by proliferation and increased oxidative stress (Lee et al., 2002).

Mitochondrial shape is a function of cellular metabolic demand and mitosis (Mishra et al., 2015; Chen and Chan, 2017). Highly proliferative cells contain more small, punctate mitochondria to efficiently segregate them into daughter cells (Chen and Chan, 2017). WT MEFs conform to this phenotype and have higher frequencies of circular mitochondria than CHIP KO (Fig. $4 H)$. We observed that relative frequency distributions for mitochondrial circularity are skewed in CHIP KO MEFs, with higher frequencies for more elongated mitochondria (circularity $<0.3$ ) than in WT (Fig. 4H). This finding of increased noncircular mitochondria in KO cells, together with our TEM results, suggests a mitochondrial ultrastructure that may vary in proliferative and nonproliferative CHIP-deficient cells, but invariably is associated with a profoundly complex structure. Because EM analysis depends on 2D transverse sectioning of cells, branching and length are not captured using this modality.

\section{CHIP plays a critical role in acute neuroprotection}

Given that CHIP plays a critical role in maintaining normal mitochondrial morphology and its expression increases in response to acute stress (Palubinsky et al., 2015), we hypothesized that acute CHIP induction is necessary for neuroprotection. Because chronic loss of CHIP causes profound changes in the proteome and intracellular milieu (Min et al., 2008; Palubinsky et al., 2015), we chose to acutely deplete rat primary neurons of endogenous CHIP using siRNA to test this hypothesis. We achieved $\sim 67.5 \%$ knock-down of CHIP $24 \mathrm{~h}$ after transfection compared with control $(p=0.0258, n=4$; Fig. $5 A)$. By $48 \mathrm{~h}$ after transfection, CHIP expression was not significantly different from control $(p=0.661$, $n=4$; Fig. 5A). Importantly, CHIP siRNA caused no changes in cellular morphology or cell viability (Fig. $5 B$ ) compared with neurons that were treated with vehicle.

To test the effect of CHIP deficiency during neuroprotective priming, we transfected neurons with CHIP siRNA followed $24 \mathrm{~h}$ later (during optimal CHIP knock-down) by a mild bioenergetic stress. CHIP depletion did not affect viability after low-level (15 min) OGD compared with nontransfected neurons (Fig. 5B). We next sought to determine the effect of CHIP depletion on neuroprotection against a lethal stressor. We subjected CHIP-depleted cultures to low-level OGD followed by 90 min OGD $24 \mathrm{~h}$ later. Although CHIP expression was uninhibited during $90 \mathrm{~min}$ of OGD, cells that were depleted of CHIP during the priming event were not afforded neuroprotection and exhibited levels of cell death comparable to lethal 90 min of OGD alone (Fig. 5B).

\section{Mitochondrial localization of CHIP is independent of its E3 ligase activity and HSP70 binding}

To eliminate changes attributed to cell passage and mitosis as observed in MEFs, we next used a superior physiological model of 

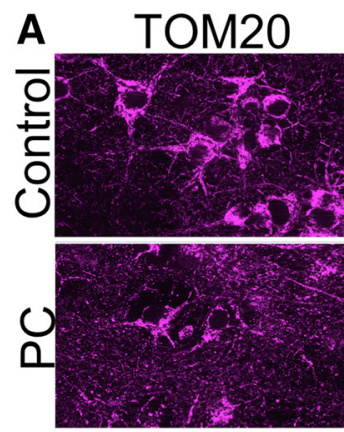

MAP2

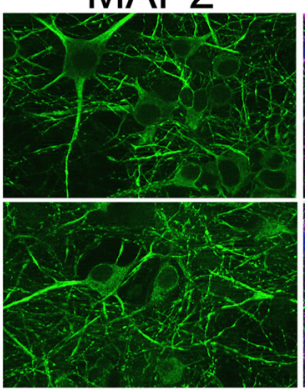

Merge

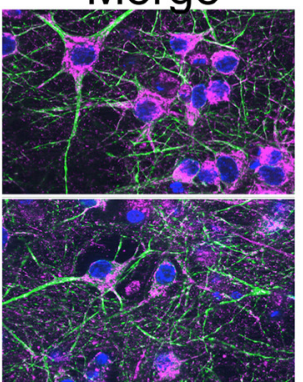

B

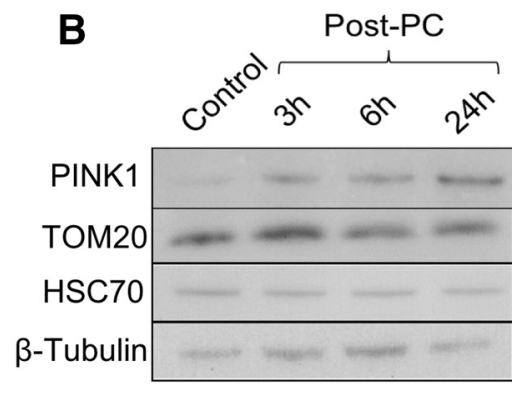

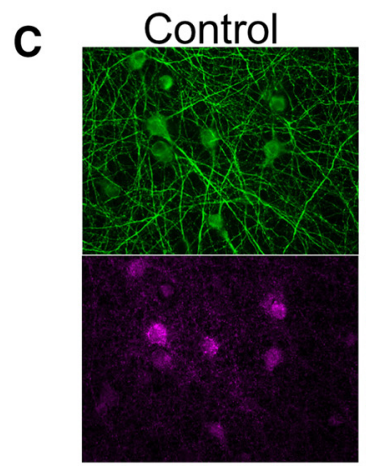
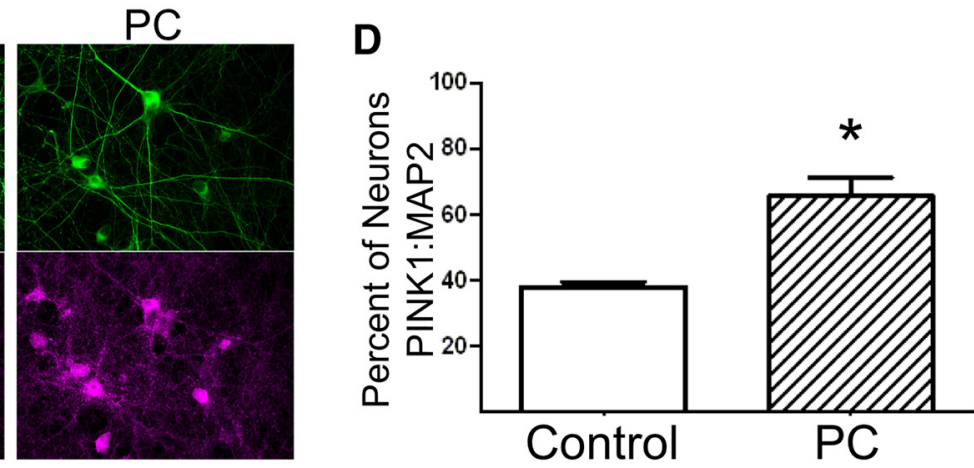

Figure 2. Low-level bioenergetic stress results in changes in mitochondrial morphology and increased expression of the mitophagy-related protein PINK1. $A$, Rat primary forebrain neurons were exposed to 15' OGD (PC), probed with antibodies recognizing TOM20 (magenta) and MAP2 (green), and ounterstained with the nuclei marker DAPI (blue). PC was associated with fragmented mitochondria (magenta), whereas neuronal processes (green) remained intact, consistent with the preservation of cell viability. $\boldsymbol{B}$, Mitochondrial stress was assessed by evaluating stabilized PINK1 3,6 , or $24 \mathrm{~h}$ after PC. Whole-cell lysates were probed with antibodies against PINK1 and the mitochondrial outer membrane protein TOM20, as well as HSC70 and $\beta$-Tubulin as loading controls. Quantification is summarized in Table 2.C, Using immunofluorescence, PINK1 (magenta) and MAP2 (green) staining revealed high levels of somatic PINK1 staining in preconditioned cells, consistent with the overall elevation in PINK1 signal in B. D. Cell counts of PINK1-positive neurons were performed by blinded investigators. PINK1 can be observed in 38\% of MAP2-positive neurons at baseline. After PC, the number of neurons expressing stabilized PINK1 significantly increases to $68 \%$ of neurons $(t=4.6, \mathrm{df}=4, p=0.01, n=3$, Student's $t$ test).

Table 2. Quantification of PINK1 and TOM20 after mild bioenergetic stress

\begin{tabular}{lllll}
\hline & & \multicolumn{3}{l}{ Fold change normalized to control } \\
\cline { 3 - 5 } & $n$ & $3 \mathrm{~h}$ & $6 \mathrm{~h}$ & $24 \mathrm{~h}$ \\
\hline PINK1 & 3 & $2.5 \pm 1.0$ & $2.6 \pm 0.9$ & $3.3 \pm 2.1$ \\
TOM20 & 4 & $1.3 \pm 0.1$ & $1.3 \pm 0.2$ & $1.2 \pm 0.2$ \\
HSC70 & 4 & $0.9 \pm 0.2$ & $1.3 \pm 0.5$ & $1.1 \pm 0.4$ \\
$\beta$-Tubulin & 4 & $1.3 \pm 0.1$ & $1.2 \pm 0.2$ & $1.2 \pm 0.1$ \\
\hline
\end{tabular}

Neurons exposed to 15' OGD were harvested 3, 6, or $24 \mathrm{~h}$ later. Whole-cell lysates were probed with antibodies against PINK1 and TOM2O, with HSC70 and $\beta$-Tubulin as loading controls (Figure 2B). Bands were quantified by ImageJ Fiji densitometry analysis. Values summarized in the table are the average band intensity relative to control \pm SEM. Significance was determined using one-way ANOVA with Bonferroni's post hoc analysis. PINK1 expression increased by $3 \mathrm{~h}$ after $0 G \mathrm{D}$ and remained increased above control levels, although the differences were not statistically significant $\left(R^{2}=0.18, F=0.588, p=0.640\right)$. TOM20 expression did not change significantly after OGD $\left(R^{2}=0.223, F=1.146, p=0.370\right)$. No significant differences were observed in loading controls HSC70 $\left(R^{2}=\right.$ $0.052, F=0.296, p=0.960)$ and $\beta$-Tubulin $\left(R^{2}=0.1255, F=0.517, p=0.760\right)$.

acute neuronal stress, subjecting post-mitotic CHIP KO primary neuronal cultures to a mild bioenergetic stress. We predicted that CHIP KO neurons would exhibit severe deficits in mitochondrial quality and that, even when CHIP was reintroduced into KO cells, it would colocalize to mitochondria in control cells given that they had lacked CHIP before transfection.

To test these hypotheses, we exposed WT and CHIP KO neurons to $15 \mathrm{~min}$ of OGD and assessed mitophagic processes using immunofluorescence staining for TOM20 as a mitochondrial marker and LC3 as a signal for autophagosome formation $6 \mathrm{~h}$ after the bioenergetic stress. WT neurons exposed to acute stress exhibited LC3-positive autophagosomes throughout the cells that contain both mitochondria and CHIP (Fig. 6A). In contrast, KO neurons exhibited much more pervasive somatic redistribution of mitochondria after the stressor compared with WT controls (Fig. 6A). In CHIP-deficient cells, we also observed elongated mitochondria that colocalized with LC3 after OGD, with fewer rounded autophagosome structures. Together with Figure 4, these data suggest that CHIP is necessary for maintaining mitochondrial morphology and suggest a role for CHIP in the mitophagic removal of dysfunctional organelles.

Quantification of colocalization was performed using Fiji Coloc2 on immunofluorescence images of WT neurons expressing TOM20 and endogenous CHIP. We found that some CHIP: TOM20 colocalization was maintained at basal levels (Fig. 6B). After mild bioenergetic stress, we found that CHIP:TOM20 colocalization does not change relative to control levels. We suspect that mitophagy occurs rapidly after the initiation of OGD.

Because CHIP does not contain a canonical mitochondrial targeting sequence, we sought to determine the structural domains necessary for CHIP localization to mitochondria. CHIP contains two primary functional domains: the N-terminal TPR domain that binds to HSPs and other TPR domain-containing enzymes and the C-terminal Ubox domain required for $\mathrm{E} 3$ ligase activity (Ballinger et al., 1999; Jiang et al., 2001). Mutations identified in patients with spinocerebellar ataxia are located in multiple domains of CHIP, leading to loss of either chaperone function or ubiquitin ligase activity (Heimdal et al., 2014; Shi et al., 2014; Synofzik et al., 2014; Bettencourt et al., 2015). If CHIP acts in ways similar to Parkin, then the C-terminal E3 ligase domain would be necessary for mitophagy and H260Q mutants would accumulate LC3-positive organelles but fail to remove them. We also introduced a TPR K30A mutation and hypothesized that, if HSC/HSP70 binding is required for mitophagy, then K30Atransfected cells would have no colocalization of constructs with mitochondria under baseline conditions or during bioenergetic stress. 
A
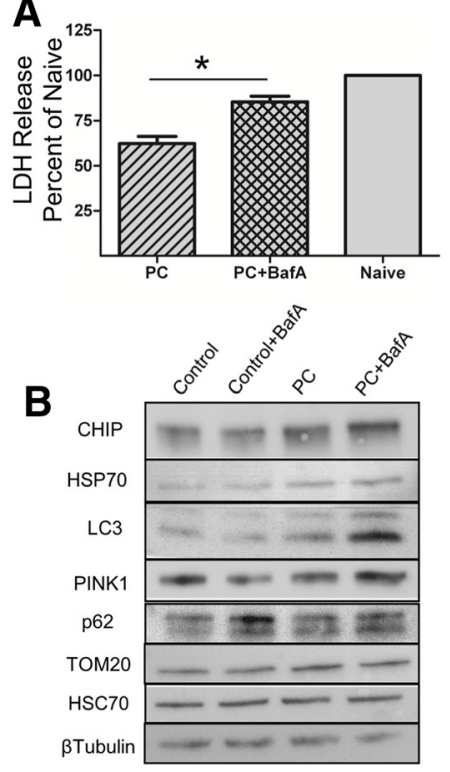

C
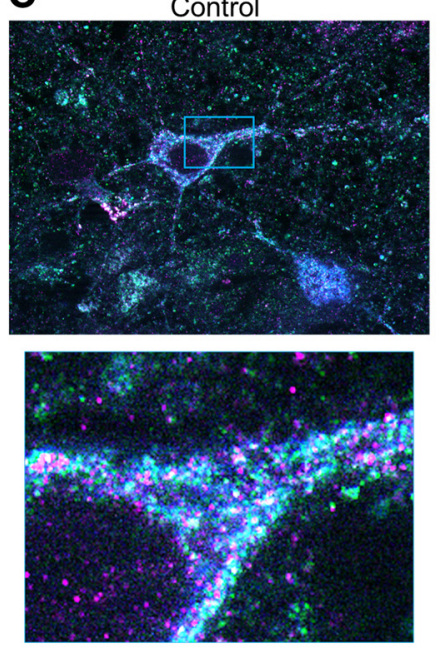

$\mathrm{CHIP}$ in Magenta

TOM20 in Blue

LC3 in Green
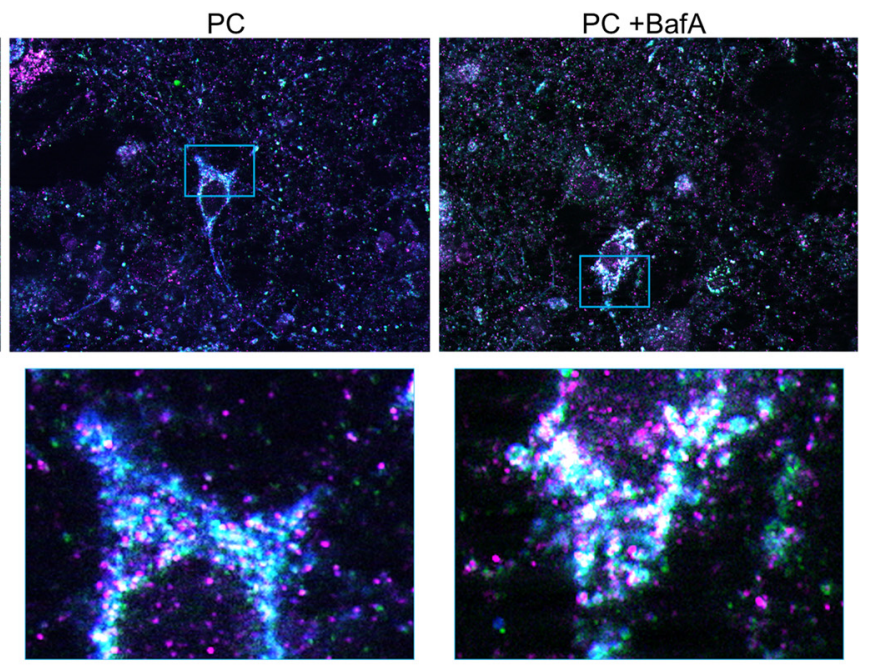

Figure 3. Autophagic signaling is required for achieving a protective response. Neurons were exposed to $15^{\prime} \mathrm{OGD}$ in the presence or absence of the BafA (1 nM), a drug that blocks vacuolar ATPases, inhibiting fusion between autophagosomes and lysosomes. $A$, Survival was assessed by LDH release $24 \mathrm{~h}$ after subsequent $90^{\prime}$ OGD as described in Figure $1 A$. Blocking autophagy resulted in $85 \%$ cell death, a significant increase compared with PC neurons without BafA. Values were normalized to 90' OGD. Data were analyzed by one-way ANOVA with Bonferroni post hoc testing. *Significance compared with preconditioned cells $\left(R^{2}=0.9041, F=42.43, p<0.05, n=4\right)$. $B$, Control neurons, neurons treated with BafA, preconditioned neurons (PC), and neurons preconditioned plus BafA (PC + BafA) were harvested for Western blotting $24 \mathrm{~h}$ after treatment. Whole-cell lysate was probed for CHIP, HSP70, LC3 (LC3-I, 18 kDa; LC3-II, 16 kDa), PINK1, p62, TOM70, HSC70, and $\beta$-Tubulin. Accumulation of LC3-II and CHIP was evident in PC + BafA. Quantification is summarized in Table 1. C, Preconditioned neurons were fixed $6 \mathrm{~h}$ after PC in the presence or absence of BafA and CHIP localization was evaluated by immunofluorescence (magenta). Autophagosomes were labeled with LC3 (green) and mitochondria were labeled with TOM20 (blue). Images were taken at $63 \times$; teal boxes re magnified to show regions of LC3 staining around CHIP-positive mitochondria. Overlap of the three labels results in white.

Table 3. Quantification of proteins following autophagy inhibition during mild bioenergetic stress

\begin{tabular}{lllll}
\hline & & \multicolumn{2}{l}{ Fold change normalized to control } \\
\cline { 3 - 5 } & $n$ & Con + BafA & OGD & OGD + BafA \\
\hline HSC70 & 4 & $1.0 \pm 0.1$ & $1.1 \pm 0.1$ & $1.2 \pm 0.1$ \\
HSP70 & 4 & $1.1 \pm 0.3$ & $1.7 \pm 0.3$ & $1.4 \pm 0.1$ \\
CHIP & 3 & $1.0 \pm 0.1$ & $1.2 \pm 0.0$ & $1.4 \pm 0.1$ \\
PINK1 & 4 & $0.8 \pm 0.2$ & $1.8 \pm 0.6$ & $1.9 \pm 0.6$ \\
TOM20 & 3 & $2.1 \pm 0.8$ & $1.8 \pm 0.4$ & $2.8 \pm 1.7$ \\
p62 & 3 & $1.5 \pm 0.1$ & $1.2 \pm 0.4$ & $2.0 \pm 0.9$ \\
LC3-I & 4 & $0.8 \pm 0.2$ & $1.0 \pm 0.3$ & $1.3 \pm 0.6$ \\
LC3-II & 4 & $0.9 \pm 0.2$ & $1.4 \pm 0.4$ & $2.3 \pm 0.9$ \\
LC3-II:LC3-I & 4 & $1.0 \pm 0.1$ & $1.5 \pm 0.4$ & $2.1 \pm 0.3$ \\
$\beta$-Tubulin & 4 & $1.1 \pm 0.1$ & $1.4 \pm 0.1$ & $1.3 \pm 0.3$ \\
\hline
\end{tabular}

Control neurons and neurons exposed to BafA (1 nM), 15' OGD, or 15' OGD + BafA were harvested $24 \mathrm{~h}$ after treatment. Whole-cell lysates were probed with antibodies against HSP70, CHIP, PINK1, TOM20, p62, and LC3, with HSC70 and $\beta$-Tubulin as loading controls (Figure 3B). Bands were quantified using ImageJ Fiji using densitometry analysis. Values summarized in the table are the average band intensity relative to control \pm SEM. Significance was determined using one-way ANOVA with Bonferroni's post hoc analysis. Whereas HSP70, PINK1, TOM20, and p62 expression increased after $0 G D$ and BafA treatment, they were not found to be statistically significant (HSP70: $R^{2}=$ $0.354, F=2.193, p=0.142 ;$ PINK1: $R^{2}=0.308, F=1.778, p=0.205 ;$ TOM20: $R^{2}=0.18, F=0.587, p=0.641$; $\left.\mathrm{p} 62: R^{2}=0.217, F=0.738, p=0.559\right)$. The ratio of $L(3-$-I to $\mathrm{L}(3-$ I increases after mild bioenergetic stress and was statistically different when cotreated with BafA $\left(R^{2}=0.501, F=4.021, p=0.034\right)$. CHIP expression also increases after OGD with BafA cotreatment $\left(R^{2}=0.722, F=6.92, p=0.013\right)$. No significant differences were observed in loading controls $\operatorname{HSC} 70\left(R^{2}=0.38, F=2.453, p=0.114\right)$ and $\beta$-Tubulin $\left(R^{2}=0.208, F=1.048, p=0.407\right)$.

Primary forebrain neurons from CHIP KO mice were cultured and transfected with plasmids expressing hCHIP, H260Q, or K30A, each fused to an mCherry expression sequence. Transfected neurons were then exposed to mild bioenergetic stress (15 min OGD) and mCherry localization was assessed after $6 \mathrm{~h}$ of recovery via ICC for TOM20 and LC3. We observed transfection of $\sim 20 \%$ of neurons.

Under baseline conditions, TOM20-positive mitochondria were well dispersed, elongated, and within a network along processes. Six hours after a mild bioenergetic stress, staining for all inducible constructs of CHIP under the human promoter was evident (Fig. $7 A-C$ ). Both human promoter-driven, nonmutated CHIP and the same construct with a H260Q Ubox inactivation mutation colocalized with mitochondria after stress (Fig. 7A, C). Interestingly, transfected CHIP with a K30A HSP70 interaction site mutation also colocalized with mitochondria that were in close proximity to LC3 labeling (Fig. $7 B$ ). These data suggest that neither E3 ligase activity nor HSP family binding is necessary for CHIP to localize to mitochondria.

Quantification of colocalization was performed using Fiji Coloc2 on immunofluorescence images of $\mathrm{KO}$ neurons expressing TOM20 and transfected hCHIP in KO neurons. When neurons from CHIP KO animals were transfected with either K30A mutant (Fig. 7B) or H260Q mutant CHIP (Fig. 7C), we observed a significant increase in CHIP:TOM20 colocalization after OGD. Similar to WT neurons (Fig. 6), we did not observe a difference in colocalization between control and after bioenergetic stress in KO neurons transfected with the nonmutated human CHIP plasmid (Fig. 7A). hCHIP does, however, localize to mitochondria even under control conditions, which we hypothesize is due to the severe disruption of mitochondrial morphology, as seen in CHIP KO MEFs and TEM (Fig. 4), as well as the limited calciumbuffering ability noted in isolated CHIP KO mitochondria ( $\mathrm{Pa}-$ lubinsky et al., 2015).

Because we saw no significant difference in mitochondrial localization of endogenous (Fig. $6 B$ ) or nonmutated CHIP after OGD (Fig. 7A), we suspect that CHIP-mediated mitophagy may be masked by the rapid turnover of organelles. To test this, KO neurons transfected with nonmutated hCHIP were treated with BafA to block autophagosome fusion with lysosomes after bioenergetic stress (Fig. 7A). Indeed, hCHIP increases colocalization with mitochondria after low-level stress when autophagy is blocked compared with control and low-level OGD alone, suggesting that CHIP- 

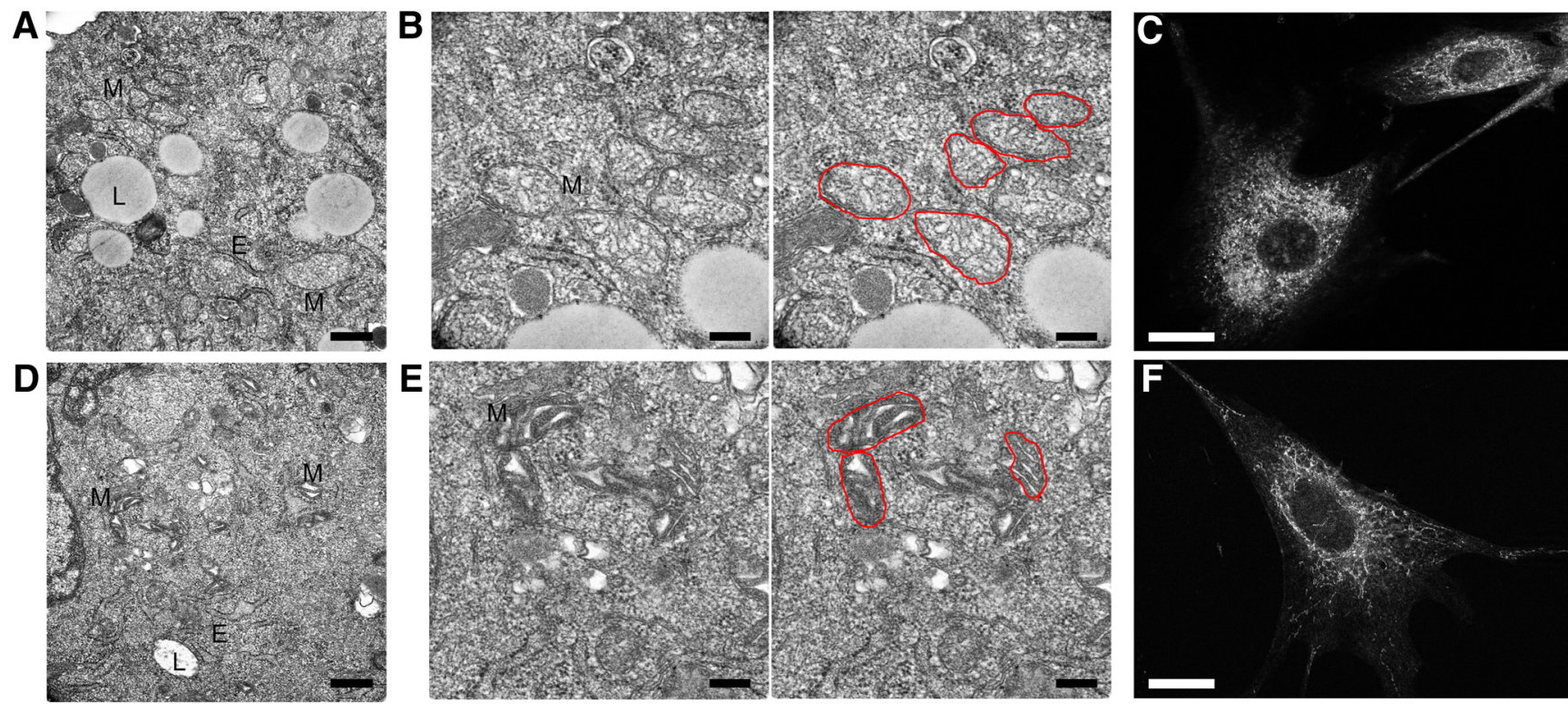

G

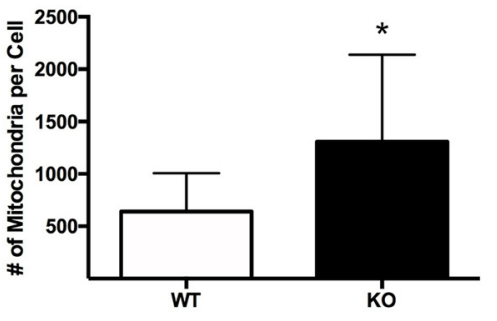

H

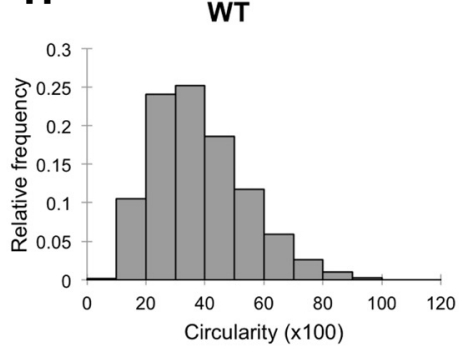

KO

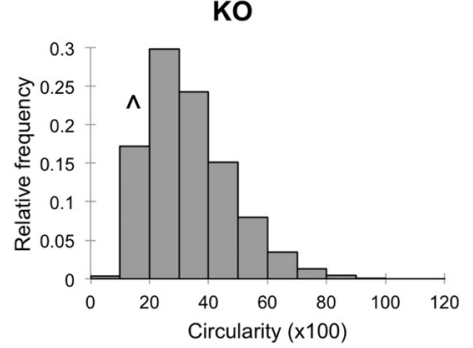

Figure 4. CHIP deficiency results in significantly increased mitochondrial number with abnormal morphological features. Immortalized MEFs were cultured from WT and CHIP KO mice. $A, B, D, E$, MEFs were grown to $60-70 \%$ confluency and fixed for TEM. Sections $(70-80 \mathrm{~nm})$ were imaged at $26000 \times$. Scale bars: $A, D, 500 \mathrm{~nm} ; \boldsymbol{B}, \boldsymbol{E}, 67,000 \times$. $A, \boldsymbol{B}$, WT MEFs have well defined mitochondrial membranes and thin inner membranes forming cristae. $\boldsymbol{D}, \boldsymbol{E}, \mathrm{KO}$ MEFs have smaller mitochondria containing unstructured cristae and thick inner membranes. E, Endoplasmic reticulum; L, lysosome; M, mitochondria. C, F, MEFs were stained with MitoTracker Orange and PFA fixed. Images used for measuring mitochondrial count, area, and perimeter were taken using a Zeiss Apotome (63X) and analyzed via ImageJ. Scale bar, $20 \mu \mathrm{m}$. G, KO MEFs exhibit significant increases in MitoTracker Orange-positive mitochondria per cell (mean $=1307$ mitochondria) compared with WT (mean $=641$ mitochondria) (Mann-Whitney $U=4236, p<0.0001$, WT $n=120, \mathrm{~K} 0 n=169$; asterisks denote significance). $\boldsymbol{H}$, Circularity was calculated using area and perimeter measurements where values closer to 0 indicate elongated or tubular mitochondria and a value of 1 indicates a perfect circle. Values were multiplied by 100 to generate histograms. KO MEFs exhibit significantly increased numbers of elongated mitochondria (Mann-Whitney $U=5.66 \mathrm{E}+08, p<0.0001$, WT $n=36042, \mathrm{~K} 0 n=38244$; $\wedge$ shift in relative frequency compared with WT). Graphs represent data from duplicate coverslips per genotype from two independent cultures, with significance determined via Mann-Whitney analysis.

tagged mitochondria are directed for autophagy (Fig. 7A). Together, these data suggest that functional Ubox and TPR domains are essential for clearance of mitochondria after bioenergetic stress but not for mitochondrial localization.

\section{Loss of CHIP changes the expression of critical bioenergetic} enzymes and mitochondrial quality control proteins

Mitochondrial transport failure, altered organelle dynamics, and changes in structure and function have been implicated in the primary pathology of an increasing number of neurodegenerative diseases (Mórotz et al., 2012; Yan et al., 2013; Serrat et al., 2014; Zhang et al., 2015). Proteomic analyses of whole brains harvested from PND35 WT and CHIP KO mice revealed a number of proteins essential for mitochondrial trafficking and energetic homeostasis that are significantly altered in CHIP $\mathrm{KO}$ animals compared with WT (Table 4).

The greatest change observed was a 10 -fold increase in the expression of ganglioside-induced differentiation associated protein (Gdap-1). Like CHIP, Gdap-1 lacks a canonical mitochondrial targeting sequence, but functions as an essential mitochondrial outer membrane protein regulating mitochondrial structure and function (Niemann et al., 2005; Otera and Mihara,
2011). Artificially increasing Gdap-1 expression in cell lines results in mitochondrial hyperfission without overt toxicity, whereas driving the expression of fusion proteins such as mitofusin 1 can reverse this phenotype (Niemann et al., 2005). The 10-fold increase in Gdap-1 observed in CHIP KO mice should drive mitochondrial fission and therefore manifest as small circular mitochondria. However, our imaging analysis and quantification of mitochondria from CHIP KO MEFs demonstrate elongated and misshapen organelles. This suggests that Gdap-1 upregulation, although significant, is unsuccessful at driving fission in a CHIPdeficient model.

Although less well understood in the context of mitochondrial dynamics, the dynamin protein family is essential for endocytosis, organelle fission, and fusion and vesicle formation (Antonny et al., 2016). Dynamin 1 and 3 are CNS specific and highly expressed in neurons (Romeu and Arola, 2014). We observed a 7.5-fold increase in expression levels of Dynamin 3 (Dnm3) in CHIP KO brains. These data are consistent with our previous report of increased levels of Dynamin-related protein 1 (Drp1) in CHIP KO mice (Lizama et al., 2018), as well as a gene dose-dependent change in Drp1 oxidation (Palubinsky et al., 2015). Like Gdap-1, increased Dnm3 and Drp1 should manifest as significant mito- 

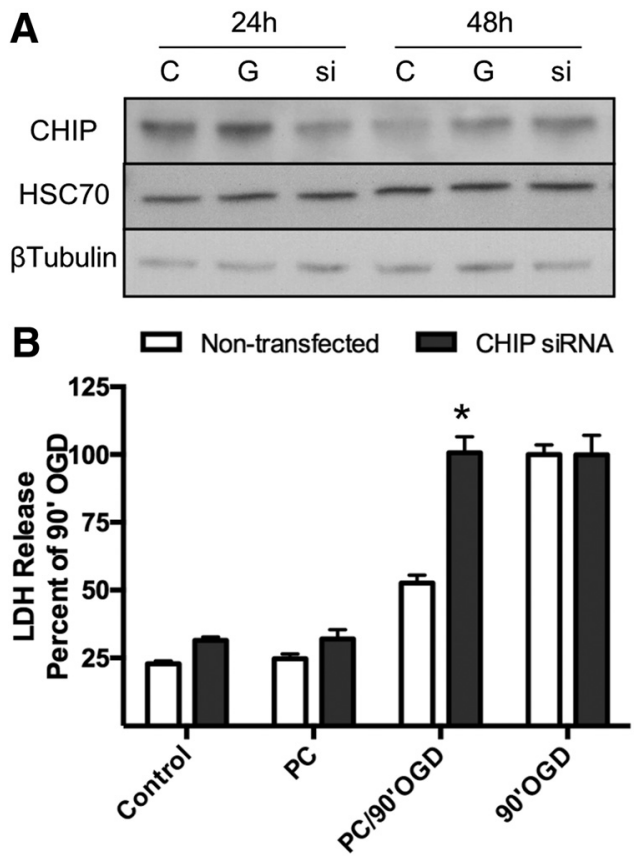

Figure 5. CHIP expression is required for achieving a protective response. Neurons were treated with vehicle (control; C), transfected with GFP (G), or transfected with GFP and $20 \mathrm{~nm}$ CHIP siRNA (si). Neurons were harvested either 24 or $48 \mathrm{~h}$ later and Western blotting was performed for CHIP using HSC70 and $\beta$-Tubulin as loading controls. A, Maximal silencing of CHIP expression (67.5\% of control; $t=4.125, \mathrm{df}=3, p=0.0258, n=4$, Student's $t$ test) was achieved $24 \mathrm{~h}$ after transfection and this time point was chosen to determine whether blocking CHIP attenuated $\mathrm{PC}$-induced neuroprotection. CHIP expression by $48 \mathrm{~h}$ was not significantly different from control ( $t=0.484, \mathrm{df}=3, p=0.661, n=4$, Student's $t$ test). No significant differences in HSC70 $\left(R^{2}=0.044, F=0.166, p=0.972, n=4\right.$, ANOVA) or $\beta$-Tubulin expression were observed $\left(R^{2}=0.189, F=0.791, p=0.571, n=4\right.$, ANOVA). $\boldsymbol{B}$, LDH released from dead or dying cells was assessed $24 \mathrm{~h}$ after $90^{\prime} \mathrm{OGD}$ as described in Figure 1 . Raw absorbance values were normalized to values obtained from $90^{\prime}$ OGD, which leads to $100 \%$ cell death. $L D H$ release data revealed that CHIP-deficient neurons were far less likely to survive $90^{\prime}$ $0 G D$, even though they had been preconditioned (mean difference compared with nontransfected $=48.08$, SE of difference $=5.706, t=8.425, \mathrm{df}=123$ ). Data represent the mean from three independent experiments, with significance determined by two-way ANOVA and Bonferroni post hoc analysis. One significant outlier was excluded by the Grubbs outlier test. Significant siRNA transfection-treatment interaction was observed $\left(F_{(3,123)}=14.62, p<0.0001\right)$. No significant differences in viability were observed between nontransfected and CHIP siRNAtransfected control cultures (mean difference $=8.595$, SE of difference $=5.622, t=1.529$, $\mathrm{df}=123$ ) and after $\mathrm{PC}$ (mean difference $=7.213$, SE of difference $=5.622, t=1.283, \mathrm{df}=$ 123) or $90^{\prime} \mathrm{OGD}$ (mean difference $=-0.006, \mathrm{SE}$ of difference $=5.622, t=0.001, \mathrm{df}=123$ ). *Significant compared with nontransfected cells at $p<0.05$.

chondrial fission, but given our analyses, these proteins are also unable to drive this process in the absence of CHIP.

CHIP deficiency also resulted in a 2.3 -fold increase in the expression of the mitochondrial trafficking protein Miro (Rhot1). This Rho GTPase is an outer mitochondrial membrane protein involved in regulating mitochondrial morphology and intracellular and intercellular trafficking. Miro is essential for ensuring ATP availability for energetically demanding neuronal signaling and communication (Tang, 2015). Overexpression of Miro1 or Miro2 increases mitochondrial length (Saotome et al., 2008), a finding that is consistent with the elongated phenotype of these organelles in CHIP-deficient cells. In addition to changing mitochondrial shape, increased Miro expression may be causally linked to changes in CHIP expression. Phosphorylation of Miro by PINK1 (Wang et al., 2011a) targets the protein for degradation by the E3 ubiquitin ligase Parkin (Liu et al., 2012; Birsa et al., 2014). Given the number of overlapping substrates between CHIP and Parkin
(Lizama et al., 2018), it is possible that CHIP promotes Miro degradation as well. Together with increased Gdap-1, Dnm3, and Drpl, we suspect that CHIP is a critical link between mitochondrial fission and subsequent mitophagy, although more studies are needed to confirm direct protein-protein interactions between CHIP and these mitochondrial targets.

In addition to molecules related to fission-fusion dynamics, we also identified several mitochondrial enzymes increased in brains from CHIP KO animals. Alcohol dehydrogenase (ADH), also termed s-nitroso glutathione terminase, is elevated 3-fold in CHIP-deficient animals. Given that ADH eliminates neurotoxic aldehydes generated by lipid peroxidation (O'Brien et al., 2005), this result is consistent with our prior report that CHIP deficiency significantly increases CNS F2t-Isoprostanes and neuroprostanes (Palubinsky et al., 2015). These species are derived from the nonenzymatic reduction of the membrane lipids arachidonic acid and docosahexaenoic acid. In addition to detoxifying aldehydes, $\mathrm{ADH}$ can bind A- $\beta$ peptide, forming a mitotoxic species that decreases complex IV activity, oxygen and neural glucose utilization and ATP formation, as well as the production of ROS (Yao et al., 2011).

The Krebs cycle enzyme malate dehydrogenase (MDH) is increased 2.2-fold in brains from CHIP KO animals. $\mathrm{MDH}$ is the final acceptor in the Krebs cycle and is increased in neural cell culture models exposed to oxidative stress (Bubber et al., 2005; Shi and Gibson, 2011). The mitochondrial-specific isoform, MDH2, interacts with the malate-aspartate shuttle, which facilitates the transfer of reducing equivalents from the cytosol to the mitochondria for oxidation (Musrati et al., 1998). Pharmacological activators of MDH and the malate-aspartate shuttle are protective in cardiac ischemia-reperfusion injury models (Støttrup et al., 2010), suggesting that this pathway is rate limiting and increased expression and activity may be part of an effort to adapt to the bioenergetic dysfunction caused by chronic loss of CHIP.

The observed decreases in glutathione S-transferase (GST) speak to the intense oxidative stress observed in a CHIP-deficient brain. Glutathione (GSH) is the most abundant cellular antioxidant, and maintaining a high ratio of reduced to oxidized glutathione (GSH:GSSG) is essential for cellular health (Halliwell and Gutteridge, 1989). GST catalyzes the conjugation of GSH to endogenous and exogenous oxidized lipids and proteins for detoxification (Strange et al., 2001). CHIP KO animals have a 4.1-fold decrease in GSTA4 expression. This antioxidant is particularly interesting in that it is dually located in the cytosol and mitochondria (Raza, 2011; Al Nimer et al., 2013). Within the mitochondria, GSTA4 detoxifies cells from the lipid peroxidation product 4hydroxynoneal generated in response to oxidative stress (Singhal et al., 2015). The decrease in GSTA4 expression we identified via proteomics corroborates our previous findings of increased protein oxidation and lipid peroxidation in CHIP-deficient animals (Palubinsky et al., 2015).

Other aspects of cellular protein and lipid oxidation profiles are also clearly affected by CHIP deficiency, including a 2.8 -fold decrease in DJ-1 expression. DJ-1 is a redox sensor that functions in repairing proteins damaged by glycation during oxidative stress. DJ-1 translocates to mitochondria in neural cells after bioenergetic stress and is secreted by injured neurons (Kaneko et al., 2014). Loss of DJ-1 increases susceptibility to cell death after acute ischemia-reperfusion in mice (Dongworth et al., 2014). Therefore, novel DJ-1-binding compounds are currently being studied in the context of Parkinson's disease therapy (Inden et al., 2017) and have the potential to be cross-purposed as neuroprotective strategies against acute oxidative stress. These data support a model in which CHIP is a critical regulator of redox 
homeostasis as DJ-1 decreases significantly in its absence, refortifying an environment of protein and lipid oxidation.

Together, these data reveal that CHIP expression is critical to mitochondrial quality control proteins, bioenergetic enzymes, and redox sensors. These results contribute to our understanding of the severe abnormalities in mitochondrial shape, cristae structure, and calcium-buffering capacity, as well as the observed increased neuronal vulnerability to mild bioenergetic stress when CHIP is absent.

\section{Discussion}

The interactions between proteins involved in mitochondrial bioenergetics, redox tone, structure, signaling, and autophagy are becoming increasingly well understood, particularly in regard to mediating responses to neurological injury and disease. Redox stress sensors such as PINK1, DJ-1, and apoptosis signaling kinases play critical roles in sensing oxidative stress, triggering mitophagy, and initiating fission and fusion of organelles. The expression and distribution of these proteins are regulated by chaperones, protein-protein interactions, redox sensitivity, ubiquitination, and degradation. In this work, we show that the chaperone-binding protein CHIP is unique among disease-associated proteins in that it is both an E3 ligase and an essential regulator of mitochondrial number and morphology in both physiological and acute pathophysiological stress signaling.

CHIP was identified as a potential regulator of acute neuronal stress in our previous studies showing increases in CHIP and HSP70 expression that correlated with the time windows of neuroprotection observed in ischemic preconditioning (Stankowski et al., 2011). Cells given a low (nonlethal) level of stress are able to upregulate endogenous protective pathways and withstand any number of subsequent injuries including OGD, hypoxia, and oxidative stress (Stetler et al., 2014). We sought to evaluate the importance of CHIP using a preconditioning model because understanding the proteins and pathways that control this endogenous form of protection could be leveraged therapeutically.

Primary neuronal cultures exposed to a short period of OGD proved to be a highly effective means to study CHIP redistribution. Here, we show that CHIP expression increases rapidly in neurons in response to bioenergetic stress, functioning as a critical regulator of neuroprotection and mitochondrial autophagic clearance. Within $6 \mathrm{~h}$ of acute stress, CHIP relocalized to mitochondrial membranes. Silencing CHIP expression with siRNA significantly increased neuronal death in response to subsequent stress. These data suggest that CHIP induction and redistribution are critical events in neurons to fend off potentially toxic events.

We initially hypothesized that, when redistributed to the mitochondria, CHIP promotes mitophagy in a manner akin to Parkin. Parkin is a well characterized E3-ubiquitin ligase with similar functional domains to CHIP and, based on cell-free assays, some redundant client proteins that are targeted for degradation (Imai et al., 2002; Kumar et al., 2012). In vitro studies of Parkin revealed its roles in mitochondrial quality control and mitophagy (Grünewald et al., 2010; Matsuda et al., 2010; Narendra et al., 2010; Rana et al., 2013; Seirafi et al., 2015).

The ability of CHIP to compensate for Parkin dysfunction was first reported more than a decade ago (Imai et al., 2002) and new studies in Drosophila show that CHIP functions downstream of PINK1 signaling, with CHIP overexpression rescuing mitophagy when Parkin is deficient (Chen et al., 2017). In our current work, we reveal that pro-fission proteins are upregulated when CHIP is absent and CHIP KO cells contain more mitochondria that are hyperfused. Increased mitochondrial fusion occurs in cells with high energetic demand and dependence on oxidative phosphorylation (Mishra et al., 2015). Given that CHIP KO cells have poor bioenergetic stores, increased oxidative stress, elevated pro-fission proteins, and hyperfused mitochondria, we conclude that CHIP is necessary for further processing of basal mitochondrial fission and subsequent mitophagy.

Together with biophysical data, it is perhaps not surprising that CHIP is unique among E3 ligases because it forms asymmetric homodimers with protruding TPR domains. These TPR domains transiently bind to the C-terminal domain of HSC/ 

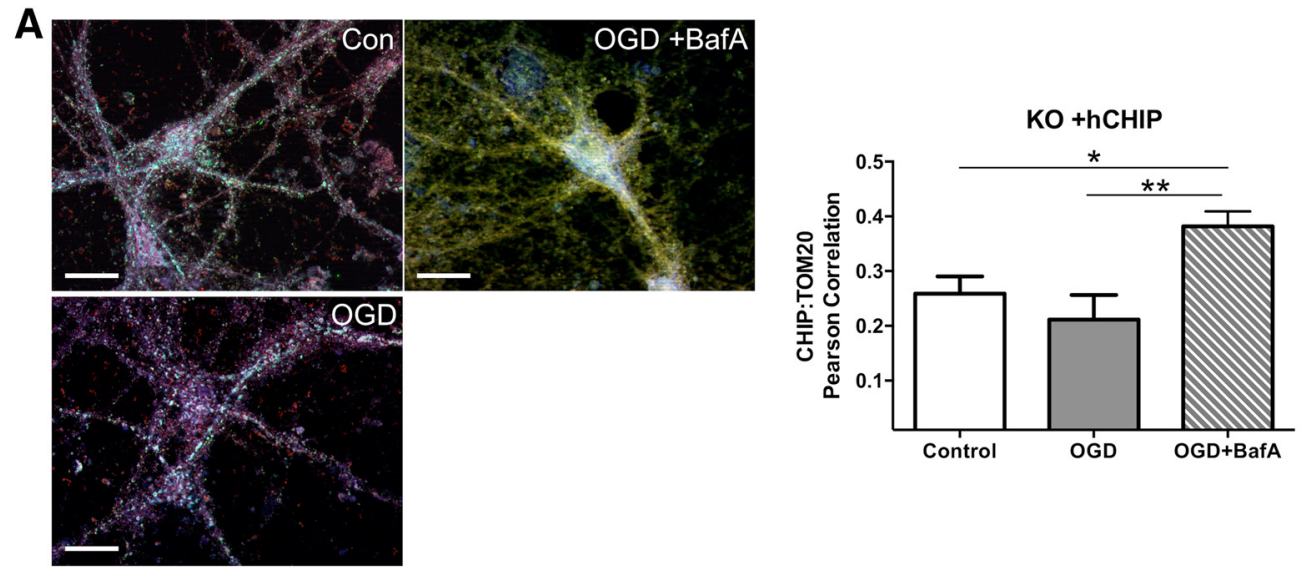

B

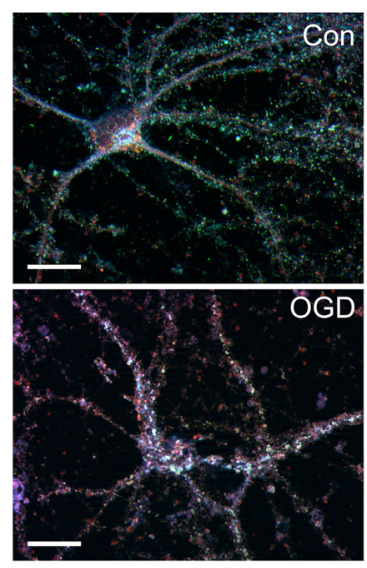

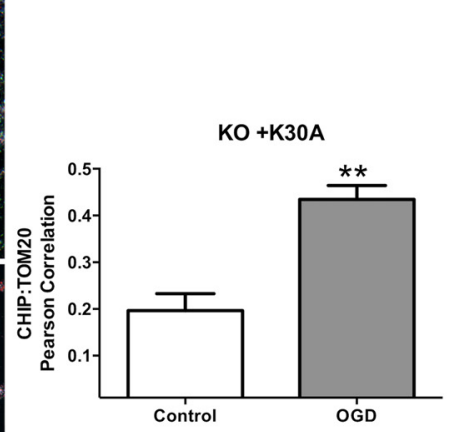

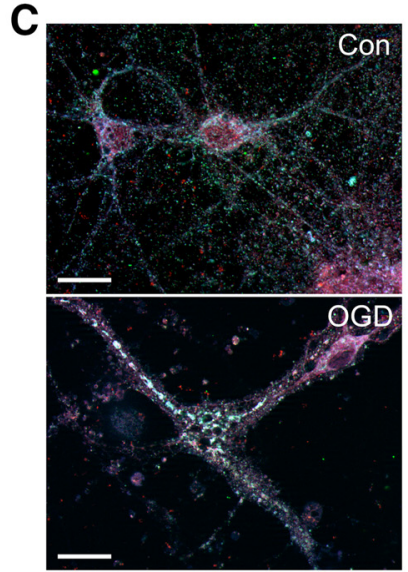

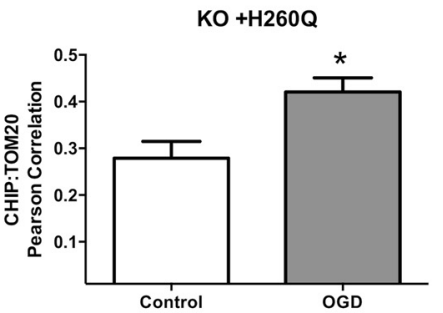

Figure 7. CHIP is necessary for maintaining mitochondrial quality control after stress, yet mitochondrial localization of CHIP is independent of the TPRand Ubox domains. $A$, CHIP KO neurons were transfected with CHIP (hCHIP) (A), K30A (B), or H260Q (C). Twenty-four hours after transfection, cultures were exposed to 15' 0GD or 15' OGD + BafA (1 nm) and PFA fixed at $6 \mathrm{~h}$. Cultures were probed with antibodies targeting TOM20 (blue) and LC3 (green). Red fluorescence is emitted from the mCherry tag linked to transfected CHIP. Scale bar, $20 \mu \mathrm{m}$. $A$, KO neurons transfected with nonmutated hCHIP (KO + hCHIP) exhibit baseline CHIP:TOM20 colocalization [Pearson correlation coefficient $(P C C)=0.26$ ] that does not significantly differ after OGD $(P C C=0.21)$. Cotreatment with BafA significantly increases CHIP:TOM20 colocalization after OGD $(P C C=0.38)$ compared with control and OGD alone $\left(R^{2}=0.09, F=3.195, p=0.023\right.$, ANOVA). $B$, KO neurons transfected with K30A (KO + K30A) demonstrate increased colocalization

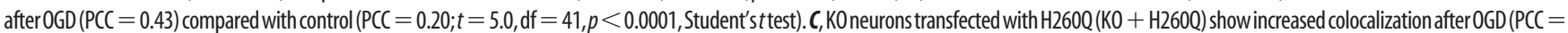
0.42 ) compared with control ( $P C C=0.28 ; t=2.813, \mathrm{df}=45, p=0.007$, Student's t test). Significance was at ${ }^{*} p<0.01$, and ${ }^{* *} p<0.0001$.

Table 4. CHIP loss changes expression of proteins involved in mitochondrial dynamics and energetics

\begin{tabular}{lc}
\hline Significantly altered proteins & \\
\hline Increased in CHIP K0 Mice & \\
Protein & Fold change \\
$\quad$ Gdap-1 & 10.2 \\
Dynamin 3 & 7.5 \\
Miro & 2.3 \\
Alcohol dehydrogenase & 3.0 \\
Malate dehydrogenase & 2.2 \\
Decreased in CHIP KO Mice & \\
Protein & Fold change \\
Glutathione S-transferase $\alpha 4$ & 4.1 \\
DJ-1 & 2.8 \\
\hline
\end{tabular}

Whole-brain lysates from WT and CHIP KO mice ( 4 male, 4 female for each genotype) were analyzed by LC-MS/MS Proteins listed are $>2$-fold increased or decreased in $\mathrm{KO}$ compared with WT based on spectral count data. Statistical significance was determined by Student's $t$ test: Gdap- $1(t=-16.053$, df $=7, p=8.846 \mathrm{E}-07)$; Dynamin 3 $(t=-29.646, \mathrm{df}=7, p=1.280 \mathrm{E}-08) ;$ Miro $(t=-7.751, \mathrm{df}=7, p=0.0001)$; alcohol dehydrogenase $(t=$ $-10.758, \mathrm{df}=7, p=1.319 \mathrm{E}-05)$; malate dehydrogenase $(t=-8.900, \mathrm{df}=7, p=4.587 \mathrm{E}-05)$; glutathione S-transferase $\alpha 4(t=14.934, \mathrm{df}=7, p=1.448 \mathrm{E}-06) ; \mathrm{DJ}-1(t=8.220 \mathrm{df}=7, p=7.664 \mathrm{E}-05)$. Statistical analysis by two-way ANOVA revealed no significant sex-genotype interaction for these proteins.

P70. The interfacing Ubox domains then add polyubiquitin chains to exposed K48 residues on client proteins (Scheufler et al., 2000; Schulman and Chen, 2005; Stankiewicz et al., 2010). Not only does CHIP lack a canonical mitochondrial localization sig- nal, but protein relocalization continued to occur even when we introduced mutations that arrest E3 ligase function (H260Q) or block HSP70 binding (K30A).

Surprisingly, mutating sites controlling HSP70 interactions or ubiquitin chain expansion enhanced CHIP association with mitochondria in response to acute stress. One interpretation of these data is that the HSP-bound/ubiquitin ligase functions of CHIP are predominantly cytosolic and that the mutations in $\mathrm{H} 260 \mathrm{Q}$ or K30A increased the free pool of CHIP capable of moving to mitochondria. An alternative interpretation is that HSP70 binding and ubiquitin ligase sites are dispensable for relocalization to mitochondria, but are required to drive downstream mitophagy signaling to degrade $\mathrm{CHIP} /$ mitochondrial complexes, which would appear as a decrease in CHIP/mitochondrial association. Such a hypothesis is supported by evidence in which HSC/HSP70 C-terminal CHIP-binding mutants increase cell vulnerability to stress-induced apoptosis (Mosser et al., 2000) and CHIP rescues mitochondrial dysfunction in a Ubox-dependent manner in PINK1 KO Drosophila models (Chen et al., 2017).

In the absence of a canonical mitochondrial targeting sequence, our data suggest that the charged helix domains of CHIP may mediate mitochondrial localization or that the TPR and Ubox domains may contain unidentified regions that bind with proteins or lipids that facilitate mitochondrial localization. Indeed, 
CHIP was recently shown to bind to lipid membranes enriched in phosphotidylinositol and phosphotidic acid and that these lipid substrates compete with chaperones for binding at the TPR domain (Kopp et al., 2017). Interestingly, however, Kopp et al. (2017) found that purified CHIP protein did not bind strongly to cardiolipin using cell-free lipid-binding assays. Cardiolipin, an inner mitochondrial membrane lipid, externalizes to the outer mitochondrial membrane in response to mitochondrial injury, interacts with LC3, and facilitates mitophagy (Chu et al., 2013). Based on our findings, further study of CHIP binding with mitochondrial lipids such as cardiolipin could prove useful for detecting lipid-protein interactions that may underlie the mitochondrial morphology and dysfunction associated with CHIP depletion.

Although H260Q and K30A mutations were selected based on known functions of CHIP primary domains, next-generation sequencing of patients with spinocerebellar ataxias has identified numerous mutations in the STUB1 gene encoding the CHIP protein. In patients with SCAR16, homozygous or compound heterozygous point mutations are spread throughout the major structural domains of CHIP, resulting in a loss of function (Heimdal et al., 2014; Shi et al., 2014; Synofzik et al., 2014; Bettencourt et al., 2015; Kawarai et al., 2016). STUB1 mutations are rare and the clinical phenotype and neuropathological features of these mutations remain poorly described. CHIP likely controls critical functions beyond the cerebellum because patients present not only with progressive limb ataxia, gait instability, and cerebellar atrophy, but also with dysarthria and mild cognitive impairment (Heimdal et al., 2014; Kawarai et al., 2016).

Genetic mutations in E3 ligases such as X-linked inhibition of apoptosis protein, Hrd1, and Parkin are associated with Parkinson's disease and other neurological disorders (Harlin et al., 2001; Goldberg et al., 2003; Kaneko et al., 2010). However, recapitulating neuronal death, particularly in Parkin KO mouse models, has largely proven unsuccessful (Perez and Palmiter, 2005).

Our data suggest that CHIP performs a more vital role in neuronal homeostasis than Parkin. Indeed, CHIP KO animals, neurons, and MEFs have high baseline levels of oxidative stress, bioenergetic dysfunction, and a hair-trigger response to injuries that should be nontoxic. Mitochondria are severely deformed with swollen cristae and are present in greater numbers when CHIP has been genetically deleted. This phenotype is unique compared with observations from other E3 ligase mutants (Stevens et al., 2015; Mukherjee and Chakrabarti, 2016; Roy et al., 2016). CHIP deficiency is debilitating because even heterozygous mice have significant motor dysfunction (McLaughlin et al., 2012). Homozygous-null mice are too frail to participate in behavioral testing and have significant oxidative dysfunction in the CNS and periphery before dying prematurely (Min et al., 2008; McLaughlin et al., 2012; Palubinsky et al., 2015). These data stand in stark contrast to Parkin-deficient models, which are neurochemically, behaviorally, and structurally indistinguishable from littermates (Goldberg et al., 2003; Palacino et al., 2004; Perez and Palmiter, 2005; Lizama et al., 2018).

The morphological and biochemical changes observed in CHIP deficient mitochondria do, however, strikingly parallel mutations in autophagy protein 5 (Atg5) that disrupt formation of the Atg12Atg5 complex. The Atg12-Atg5 conjugate exhibits E3 ligase-like activity, facilitating lipidation of LC3 family members (Otomo et al., 2013). Although mice with complete deletion of Atg5 die shortly after birth (Yoshii et al., 2016), Atg5 mutations have been identified in patients with ataxia and are associated with loss of autophagic signaling in conditional KO models (Kim et al., 2016). Our data support an "Atg-5-like" role for CHIP in normal and pathological neuronal mitophagy. Because CHIP-null animals are not embryonically lethal, CHIP-deficient mice may also provide a rigorous animal model for studying premature aging and susceptibility to neurological injury.

\section{References}

Al Nimer F, Ström M, Lindblom R, Aeinehband S, Bellander BM, Nyengaard JR, Lidman O, Piehl F (2013) Naturally occurring variation in the glutathione-S-transferase 4 gene determines neurodegeneration after traumatic brain injury. Antioxid Redox Signal 18:784-794. CrossRef Medline

Antonny B, Burd C, De Camilli P, Chen E, Daumke O, Faelber K, Ford M, Frolov VA, Frost A, Hinshaw JE, Kirchhausen T, Kozlov MM, Lenz M, Low HH, McMahon H, Merrifield C, Pollard TD, Robinson PJ, Roux A, Schmid S (2016) Membrane fission by dynamin: what we know and what we need to know. EMBO J 35:2270-2284. CrossRef Medline

Archer SL (2013) Mitochondrial dynamics-mitochondrial fission and fusion in human diseases. N Engl J Med 369:2236-2251. CrossRef Medline

Ballinger CA, Connell P, Wu Y, Hu Z, Thompson LJ, Yin LY, Patterson C (1999) Identification of CHIP, a novel tetratricopeptide repeatcontaining protein that interacts with heat shock proteins and negatively regulates chaperone functions. Mol Cell Biol 19:4535-4545. CrossRef Medline

Bettencourt C, de Yébenes JG, López-Sendón JL, Shomroni O, Zhang X, Qian SB, Bakker IM, Heetveld S, Ros R, Quintáns B, Sobrido MJ, Bevova MR, Jain S, Bugiani M, Heutink P, Rizzu P (2015) Clinical and neuropathological features of spastic ataxia in a spanish family with novel compound heterozygous mutations in STUB1. Cerebellum 14:378-381. CrossRef Medline

Birsa N, Norkett R, Wauer T, Mevissen TE, Wu HC, Foltynie T, Bhatia K, Hirst WD, Komander D, Plun-Favreau H, Kittler JT (2014) Lysine 27 ubiquitination of the mitochondrial transport protein miro is dependent on serine 65 of the parkin ubiquitin ligase. J Biol Chem 289:14569-14582. CrossRef Medline

Brown JE, Zeiger SL, Hettinger JC, Brooks JD, Holt B, Morrow JD, Musiek ES, Milne G, McLaughlin B (2010) Essential role of the redox-sensitive kinase p66shc in determining energetic and oxidative status and cell fate in neuronal preconditioning. J Neurosci 30:5242-5252. CrossRef Medline

Bubber P, Haroutunian V, Fisch G, Blass JP, Gibson GE (2005) Mitochondrial abnormalities in alzheimer brain: mechanistic implications. Ann Neurol 57:695-703. CrossRef Medline

Chen H, Chan DC (2017) Mitochondrial dynamics in regulating the unique phenotypes of cancer and stem cells. Cell Metab 26:39-48. CrossRef Medline

Chen J, Xue J, Ruan J, Zhao J, Tang B, Duan R (2017) Drosophila CHIP protects against mitochondrial dysfunction by acting downstream of Pink1 in parallel with parkin. FASEB J 31:5234-5245. CrossRef Medline

Chen Y, Stevens B, Chang J, Milbrandt J, Barres BA, Hell JW (2008) NS21: redefined and modified supplement B27 for neuronal cultures. J Neurosci Methods 171:239-247. CrossRef Medline

Chu CT, et al. (2013) Cardiolipin externalization to the outer mitochondrial membrane acts as an elimination signal for mitophagy in neuronal cells. Nat Cell Biol 15:1197-1205. CrossRef Medline

Dai Q, Zhang C, Wu Y, McDonough H, Whaley RA, Godfrey V, Li HH, Madamanchi N, Xu W, Neckers L, Cyr D, Patterson C (2003) CHIP activates HSF1 and confers protection against apoptosis and cellular stress. EMBO J 22:5446-5458. CrossRef Medline

Dongworth RK, Mukherjee UA, Hall AR, Astin R, Ong SB, Yao Z, Dyson A, Szabadkai G, Davidson SM, Yellon DM, Hausenloy DJ (2014) DJ-1 protects against cell death following acute cardiac ischemia-reperfusion injury. Cell Death Dis 5:e1082. CrossRef Medline

Franklin TB, Krueger-Naug AM, Clarke DB, Arrigo AP, Currie RW (2005) The role of heat shock proteins Hsp70 and Hsp27 in cellular protection of the central nervous system. Int J Hyperthermia 21:379-392. CrossRef Medline

Gestwicki JE, Garza D (2012) Protein quality control in neurodegenerative disease. Prog Mol Biol Transl Sci 107:327-353. CrossRef Medline

Goldberg MS, Fleming SM, Palacino JJ, Cepeda C, Lam HA, Bhatnagar A, Meloni EG, Wu N, Ackerson LC, Klapstein GJ, Gajendiran M, Roth BL, Chesselet MF, Maidment NT, Levine MS, Shen J (2003) Parkin-deficient mice exhibit nigrostriatal deficits but not loss of dopaminergic neurons. J Biol Chem 278:43628-43635. CrossRef Medline

Greene AW, Grenier K, Aguileta MA, Muise S, Farazifard R, Haque ME, 
McBride HM, Park DS, Fon EA (2012) Mitochondrial processing peptidase regulates PINK1 processing, import and parkin recruitment. EMBO Rep 13:378-385. CrossRef Medline

Grünewald A, Voges L, Rakovic A, Kasten M, Vandebona H, Hemmelmann C, Lohmann K, Orolicki S, Ramirez A, Schapira AH, Pramstaller PP, Sue CM, Klein C (2010) Mutant parkin impairs mitochondrial function and morphology in human fibroblasts. PLoS One 5:e12962. CrossRef Medline

Halliwell B, Gutteridge JMC (1989) Free radicals in biology and medicine, Ed 2. New York, NY: OUP.

Ham AJ (2005) Proteolytic digestion protocols. In: The encyclopedia of mass spectrometry (Caprioli RM, Gross ML, eds), pp 10-17. Kidlington, Oxford, UK: Elsevier.

Harlin H, Reffey SB, Duckett CS, Lindsten T, Thompson CB (2001) Characterization of XIAP-deficient mice. Mol Cell Biol 21:3604-3608. CrossRef Medline

Hayer SN, Deconinck T, Bender B, Smets K, Züchner S, Reich S, Schöls L, Schüle R, De Jonghe P, Baets J, Synofzik M (2017) STUB1/CHIP mutations cause gordon holmes syndrome as part of a widespread multisystemic neurodegeneration: evidence from four novel mutations. Orphanet J Rare Dis 12:31. CrossRef Medline

Heimdal K, Sanchez-Guixé M, Aukrust I, Bollerslev J, Bruland O, Jablonski GE, Erichsen AK, Gude E, Koht JA, Erdal S, Fiskerstrand T, Haukanes BI, Boman H, Bjørkhaug L, Tallaksen CM, Knappskog PM, Johansson S (2014) STUB1 mutations in autosomal recessive ataxias - evidence for mutation-specific clinical heterogeneity. Orphanet J Rare Dis 9:146. CrossRef Medline

Imai Y, Soda M, Hatakeyama S, Akagi T, Hashikawa T, Nakayama KI, Takahashi R (2002) CHIP is associated with parkin, a gene responsible for familial Parkinson's disease, and enhances its ubiquitin ligase activity. Mol Cell 10:55-67. CrossRef Medline

Inden M, Yanagisawa D, Hijioka M, Ariga H, Kitamura Y (2017) Therapeutic activities of DJ-1 and its binding compounds against neurodegenerative diseases. Adv Exp Med Biol 1037:187-202. CrossRef Medline

Jiang J, Ballinger CA, Wu Y, Dai Q, Cyr DM, Höhfeld J, Patterson C (2001) CHIP is a U-box-dependent E3 ubiquitin ligase: identification of $\mathrm{Hsc70}$ as a target for ubiquitylation. J Biol Chem 276:42938-42944. CrossRef Medline

Jin SM, Youle RJ (2013) The accumulation of misfolded proteins in the mitochondrial matrix is sensed by PINK1 to induce PARK2/Parkinmediated mitophagy of polarized mitochondria. Autophagy 9:1750-1757. CrossRef Medline

Kaneko M, Koike H, Saito R, Kitamura Y, Okuma Y, Nomura Y (2010) Loss of HRD1-mediated protein degradation causes amyloid precursor protein accumulation and amyloid-beta generation. J Neurosci 30:39243932. CrossRef Medline

Kaneko Y, Tajiri N, Shojo H, Borlongan CV (2014) Oxygen-glucosedeprived rat primary neural cells exhibit DJ-1 translocation into healthy mitochondria: a potent stroke therapeutic target. CNS Neurosci Ther 20:275-281. CrossRef Medline

Kawajiri S, Saiki S, Sato S, Sato F, Hatano T, Eguchi H, Hattori N (2010) PINK1 is recruited to mitochondria with parkin and associates with LC3 in mitophagy. FEBS Lett 584:1073-1079. CrossRef Medline

Kawarai T, Miyamoto R, Shimatani Y, Orlacchio A, Kaji R (2016) Choreoathetosis, dystonia, and myoclonus in 3 siblings with autosomal recessive spinocerebellar ataxia type 16. JAMA Neurol 73:888-890. CrossRef Medline

Kessner D, Chambers M, Burke R, Agus D, Mallick P (2008) ProteoWizard: open source software for rapid proteomics tools development. Bioinformatics 24:2534-2536. CrossRef Medline

Kim M, et al (2016) Mutation in ATG5 reduces autophagy and leads to ataxia with developmental delay. Elife 5:e12245. CrossRef Medline

Kim S, Pevzner PA (2014) MS-GF+ makes progress towards a universal database search tool for proteomics. Nat Commun 5:5277. CrossRef Medline

Klionsky DJ, Abdelmohsen K, Abe A, Abedin MJ, Abeliovich H, Acevedo Arozena A, Adachi H, Adams CM, Adams PD, Adeli K, Adhihetty PJ, Adler SG, Agam G, Agarwal R, Aghi MK, Agnello M, Agostinis P, Aguilar PV, Aguirre-Ghiso J, Airoldi EM, et al (2016) Guidelines for the use and interpretation of assays for monitoring autophagy (3rd edition). Autophagy 12:1-222. CrossRef Medline

Kopp Y, Lang WH, Schuster TB, Martinez-Limon A, Hofbauer HF, Ernst R, Calloni G, Vabulas RM (2017) CHIP as a membrane-shuttling proteostasis sensor. Elife 6.

Kubli DA, Zhang X, Lee Y, Hanna RA, Quinsay MN, Nguyen CK, Jimenez R,
Petrosyan S, Murphy AN, Gustafsson AB (2013) Parkin protein deficiency exacerbates cardiac injury and reduces survival following myocardial infarction. J Biol Chem 288:915-926. CrossRef Medline

Kumar P, Pradhan K, Karunya R, Ambasta RK, Querfurth HW (2012) Cross-functional E3 ligases parkin and C-terminus Hsp70-interacting protein in neurodegenerative disorders. J Neurochem 120:350-370. CrossRef Medline

Lee HC, Yin PH, Chi CW, Wei YH (2002) Increase in mitochondrial mass in human fibroblasts under oxidative stress and during replicative cell senescence. J Biomed Sci 9:517-526. CrossRef Medline

Liu S, Sawada T, Lee S, Yu W, Silverio G, Alapatt P, Millan I, Shen A, Saxton W, Kanao T, Takahashi R, Hattori N, Imai Y, Lu B (2012) Parkinson's disease-associated kinase PINK1 regulates Miro protein level and axonal transport of mitochondria. PLoS Genet 8:e1002537. CrossRef Medline

Lizama BN, Palubinsky AM, McLaughlin B (2018) Alterations in the E3 ligases Parkin and CHIP result in unique metabolic signaling defects and mitochondrial quality control issues. Neurochem Int 117:139-155. CrossRef Medline

Ma ZQ, Dasari S, Chambers MC, Litton MD, Sobecki SM, Zimmerman LJ, Halvey PJ, Schilling B, Drake PM, Gibson BW, Tabb DL (2009) IDPicker 2.0: improved protein assembly with high discrimination peptide identification filtering. J Proteome Res 8:3872-3881. CrossRef Medline

Matsuda N, Sato S, Shiba K, Okatsu K, Saisho K, Gautier CA, Sou YS, Saiki S, Kawajiri S, Sato F, Kimura M, Komatsu M, Hattori N, Tanaka K (2010) PINK1 stabilized by mitochondrial depolarization recruits parkin to damaged mitochondria and activates latent parkin for mitophagy. J Cell Biol 189:211-221. CrossRef Medline

McLaughlin B, Hartnett KA, Erhardt JA, Legos JJ, White RF, Barone FC, Aizenman E (2003) Caspase 3 activation is essential for neuroprotection in preconditioning. Proc Natl Acad Sci U S A 100:715-720. CrossRef Medline

McLaughlin B, Buendia MA, Saborido TP, Palubinsky AM, Stankowski JN, Stanwood GD (2012) Haploinsufficiency of the E3 ubiquitin ligase $\mathrm{C}$-terminus of heat shock cognate 70 interacting protein (CHIP) produces specific behavioral impairments. PLoS One 7:e36340. CrossRef Medline

Min JN, Whaley RA, Sharpless NE, Lockyer P, Portbury AL, Patterson C (2008) CHIP deficiency decreases longevity, with accelerated aging phenotypes accompanied by altered protein quality control. Mol Cell Biol 28:4018-4025. CrossRef Medline

Mishra P, Varuzhanyan G, Pham AH, Chan DC (2015) Mitochondrial dynamics is a distinguishing feature of skeletal muscle fiber types and regulates organellar compartmentalization. Cell Metab 22:1033-1044. CrossRef Medline

Mórotz GM, De Vos KJ, Vagnoni A, Ackerley S, Shaw CE, Miller CC (2012) Amyotrophic lateral sclerosis-associated mutant VAPBP56S perturbs calcium homeostasis to disrupt axonal transport of mitochondria. Hum Mol Genet 21:1979-1988. CrossRef Medline

Mosser DD, Caron AW, Bourget L, Meriin AB, Sherman MY, Morimoto RI, Massie B (2000) The chaperone function of hsp70 is required for protection against stress-induced apoptosis. Mol Cell Biol 20:7146-7159. CrossRef Medline

Mukherjee R, Chakrabarti O (2016) Regulation of Mitofusin1 by mahogunin ring finger- 1 and the proteasome modulates mitochondrial fusion. Biochim Biophys Acta 1863:3065-3083. CrossRef Medline

Musrati RA, Kollárová M, Mernik N, Mikulásová D (1998) Malate dehydrogenase: distribution, function and properties. Gen Physiol Biophys 17: 193-210. Medline

Narendra DP, Jin SM, Tanaka A, Suen DF, Gautier CA, Shen J, Cookson MR, Youle RJ (2010) PINK1 is selectively stabilized on impaired mitochondria to activate Parkin. PLoS Biol 8:e1000298. CrossRef Medline

Niemann A, Ruegg M, La Padula V, Schenone A, Suter U (2005) Ganglioside-induced differentiation associated protein 1 is a regulator of the mitochondrial network: new implications for charcot-marie-tooth disease. J Cell Biol 170:1067-1078. CrossRef Medline

O’Brien PJ, Siraki AG, Shangari N (2005) Aldehyde sources, metabolism, molecular toxicity mechanisms, and possible effects on human health. Crit Rev Toxicol 35:609-662. CrossRef Medline

Otera H, Mihara K (2011) Molecular mechanisms and physiologic functions of mitochondrial dynamics. J Biochem 149:241-251. CrossRef Medline

Otomo C, Metlagel Z, Takaesu G, Otomo T (2013) Structure of the human 
ATG12 ATG5 conjugate required for LC3 lipidation in autophagy. Nat Struct Mol Biol 20:59-66. CrossRef Medline

Palacino JJ, Sagi D, Goldberg MS, Krauss S, Motz C, Wacker M, Klose J, Shen J (2004) Mitochondrial dysfunction and oxidative damage in parkindeficient mice. J Biol Chem 279:18614-18622. CrossRef Medline

Palubinsky AM, Stankowski JN, Kale AC, Codreanu SG, Singer RJ, Liebler DC, Stanwood GD, McLaughlin B (2015) CHIP is an essential determinant of neuronal mitochondrial stress signaling. Antioxid Redox Signal 23:535-549. CrossRef Medline

Perez FA, Palmiter RD (2005) Parkin-deficient mice are not a robust model of parkinsonism. Proc Natl Acad Sci U S A 102:2174-2179. CrossRef Medline

Qian SB, McDonough H, Boellmann F, Cyr DM, Patterson C (2006) CHIPmediated stress recovery by sequential ubiquitination of substrates and Hsp70. Nature 440:551-555. CrossRef Medline

Rana A, Rera M, Walker DW (2013) Parkin overexpression during aging reduces proteotoxicity, alters mitochondrial dynamics, and extends lifespan. Proc Natl Acad Sci U S A 110:8638-8643. CrossRef Medline

Raza H (2011) Dual localization of glutathione S-transferase in the cytosol and mitochondria: implications in oxidative stress, toxicity and disease. FEBS J 278:4243-4251. CrossRef Medline

Romeu A, Arola L (2014) Classical dynamin DNM1 and DNM3 genes attain maximum expression in the normal human central nervous system. BMC Res Notes 7:188. CrossRef Medline

Roy M, Itoh K, Iijima M, Sesaki H (2016) Parkin suppresses Drp1independent mitochondrial division. Biochem Biophys Res Commun 475:283-288. CrossRef Medline

Saotome M, Safiulina D, Szabadkai G, Das S, Fransson A, Aspenstrom P, Rizzuto R, Hajnóczky G (2008) Bidirectional Ca2+-dependent control of mitochondrial dynamics by the miro GTPase. Proc Natl Acad Sci U S A 105:20728-20733. CrossRef Medline

Scheufler C, Brinker A, Bourenkov G, Pegoraro S, Moroder L, Bartunik H, Hartl FU, Moarefi I (2000) Structure of TPR domain-peptide complexes: critical elements in the assembly of the Hsp70-Hsp90 multichaperone machine. Cell 101:199-210. CrossRef Medline

Schulman BA, Chen ZJ (2005) Protein ubiquitination: CHIPping away the symmetry. Mol Cell 20:653-655. CrossRef Medline

Seirafi M, Kozlov G, Gehring K (2015) Parkin structure and function. FEBS J 282:2076-2088. CrossRef Medline

Serrat R, Mirra S, Figueiro-Silva J, Navas-Pérez E, Quevedo M, LópezDoménech G, Podlesniy P, Ulloa F, Garcia-Fernàndez J, Trullas R, Soriano E (2014) The Armc10/SVH gene: genome context, regulation of mitochondrial dynamics and protection against abeta-induced mitochondrial fragmentation. Cell Death Dis 5:e1163. CrossRef Medline

Shi CH, Schisler JC, Rubel CE, Tan S, Song B, McDonough H, Xu L, Portbury AL, Mao CY, True C, Wang RH, Wang QZ, Sun SL, Seminara SB, Patterson C, Xu YM (2014) Ataxia and hypogonadism caused by the loss of ubiquitin ligase activity of the $\mathrm{U}$ box protein CHIP. Hum Mol Genet 23:1013-1024. CrossRef Medline

Shi Q, Gibson GE (2011) Up-regulation of the mitochondrial malate dehydrogenase by oxidative stress is mediated by miR-743a. J Neurochem 118:440-448. CrossRef Medline

Singhal SS, Singh SP, Singhal P, Horne D, Singhal J, Awasthi S (2015) Antioxidant role of glutathione S-transferases: 4-hydroxynonenal, a key molecule in stress-mediated signaling. Toxicol Appl Pharmacol 289:361-370. CrossRef Medline

Stankiewicz M, Nikolay R, Rybin V, Mayer MP (2010) CHIP participates in protein triage decisions by preferentially ubiquitinating Hsp70-bound substrates. FEBS J 277:3353-3367. CrossRef Medline

Stankowski JN, Zeiger SL, Cohen EL, DeFranco DB, Cai J, McLaughlin B (2011) C-terminus of heat shock cognate 70 interacting protein increases following stroke and impairs survival against acute oxidative stress. Antioxid Redox Signal 14:1787-1801. CrossRef Medline

Stetler RA, Leak RK, Gan Y, Li P, Zhang F, Hu X, Jing Z, Chen J, Zigmond MJ, Gao Y (2014) Preconditioning provides neuroprotection in models of
CNS disease: paradigms and clinical significance. Prog Neurobiol 114: 58-83. CrossRef Medline

Stevens DA, Lee Y, Kang HC, Lee BD, Lee YI, Bower A, Jiang H, Kang SU, Andrabi SA, Dawson VL, Shin JH, Dawson TM (2015) Parkin loss leads to PARIS-dependent declines in mitochondrial mass and respiration. Proc Natl Acad Sci U S A 112:11696-11701. CrossRef Medline

Støttrup NB, Løfgren B, Birkler RD, Nielsen JM, Wang L, Caldarone CA, Kristiansen SB, Contractor H, Johannsen M, Bøtker HE, Nielsen TT (2010) Inhibition of the malate-aspartate shuttle by pre-ischaemic aminooxyacetate loading of the heart induces cardioprotection. Cardiovasc Res 88:257-266. CrossRef Medline

Strange RC, Spiteri MA, Ramachandran S, Fryer AA (2001) Glutathione-Stransferase family of enzymes. Mutat Res 482:21-26. CrossRef Medline

Synofzik M, Schüle R, Schulze M, Gburek-Augustat J, Schweizer R, Schirmacher A, Krägeloh-Mann I, Gonzalez M, Young P, Züchner S, Schöls L, Bauer P (2014) Phenotype and frequency of STUB1 mutations: nextgeneration screenings in caucasian ataxia and spastic paraplegia cohorts. Orphanet J Rare Dis 9:57. CrossRef Medline

Tabb DL, Fernando CG, Chambers MC (2007) MyriMatch: highly accurate tandem mass spectral peptide identification by multivariate hypergeometric analysis. J Proteome Res 6:654-661. CrossRef Medline

Tang BL (2015) MIRO GTPases in mitochondrial transport, homeostasis and pathology. Cells 5:E1. CrossRef Medline

Wang X, Winter D, Ashrafi G, Schlehe J, Wong YL, Selkoe D, Rice S, Steen J, LaVoie MJ, Schwarz TL (2011a) PINK1 and parkin target miro for phosphorylation and degradation to arrest mitochondrial motility. Cell 147: 893-906. CrossRef Medline

Wang Y, Yang F, Gritsenko MA, Wang Y, Clauss T, Liu T, Shen Y, Monroe ME, Lopez-Ferrer D, Reno T, Moore RJ, Klemke RL, Camp DG 2nd, Smith RD (2011b) Reversed-phase chromatography with multiple fraction concatenation strategy for proteome profiling of human MCF10A cells. Proteomics 11:2019-2026. CrossRef Medline

Xu J (2005) Preparation, culture, and immortalization of mouse embryonic fibroblasts. Curr Protoc Mol Biol Chapter 28:Unit 28.1. CrossRef Medline

Xu Z, Kohli E, Devlin KI, Bold M, Nix JC, Misra S (2008) Interactions between the quality control ubiquitin ligase CHIP and ubiquitin conjugating enzymes. BMC Struct Biol 8:26. CrossRef Medline

Yan MH, Wang X, Zhu X (2013) Mitochondrial defects and oxidative stress in alzheimer disease and parkinson disease. Free Radic Biol Med 62:90101. CrossRef Medline

Yao J, Du H, Yan S, Fang F, Wang C, Lue LF, Guo L, Chen D, Stern DM, Gunn Moore FJ, Xi Chen J, Arancio O, Yan SS (2011) Inhibition of amyloidbeta (Abeta) peptide-binding alcohol dehydrogenase-abeta interaction reduces abeta accumulation and improves mitochondrial function in a mouse model of Alzheimer's disease. J Neurosci 31:2313-2320. CrossRef Medline

Ye Z, Needham PG, Estabrooks SK, Whitaker SK, Garcia BL, Misra S, Brodsky JL, Camacho CJ (2017) Symmetry breaking during homodimeric assembly activates an E3 ubiquitin ligase. Sci Rep 7:1789. CrossRef Medline

Yoshii SR, Kuma A, Akashi T, Hara T, Yamamoto A, Kurikawa Y, Itakura E, Tsukamoto S, Shitara H, Eishi Y, Mizushima N (2016) Systemic analysis of Atg5-null mice rescued from neonatal lethality by transgenic ATG5 expression in neurons. Dev Cell 39:116-130. CrossRef Medline

Zeiger SL, McKenzie JR, Stankowski JN, Martin JA, Cliffel DE, McLaughlin B (2010) Neuron specific metabolic adaptations following multi-day exposures to oxygen glucose deprivation. Biochim Biophys Acta 1802:10951104. CrossRef Medline

Zhang F, Wang W, Siedlak SL, Liu Y, Liu J, Jiang K, Perry G, Zhu X, Wang X (2015) Mirol deficiency in amyotrophic lateral sclerosis. Front Aging Neurosci 7:100. CrossRef Medline

Zhang M, Windheim M, Roe SM, Peggie M, Cohen P, Prodromou C, Pearl LH (2005) Chaperoned ubiquitylation-crystal structures of the CHIP U box E3 ubiquitin ligase and a CHIP-Ubc13-Uevla complex. Mol Cell 20:525-538. CrossRef Medline 